\title{
Tetrakis(dialkylamino)phosphonium Polyelectrolytes Prepared by Reversible Addition-Fragmentation Chain Transfer Polymerization
}

C. Tyler Womble, ${ }^{\dagger}$ Geoffrey W. Coates, ${ }^{\ddagger}$ Krzysztof Matyjaszewski, ${ }^{\dagger}$ and Kevin J. T. Noonan $^{\dagger}$

${ }^{\dagger}$ Department of Chemistry, Carnegie Mellon University, Pittsburgh, Pennsylvania 15213-2617 (USA)

${ }^{\ddagger}$ Department of Chemistry and Chemical Biology, Baker Laboratory, Cornell University, Ithaca, New York 14853-1301 (USA)

Corresponding author: noonan@andrew.cmu.edu, 1-412-268-3128

Table of Contents

Materials and Methods .S4-S5

Experimental Procedures

S6-S10

Scheme S1. Phosphonium Monomer Synthesis S6

General Polymerization Procedure S11-12

Scheme S2. RAFT Copolymerization of Styrene and $\mathbf{1 .}$ S11

NMR Spectra S13-S19

Figure S1. ${ }^{1} \mathrm{H}$ NMR spectrum of cyclohexylphosphorimidoyl trichloride. $\mathrm{S} 13$

Figure S2. ${ }^{31} \mathrm{P}\left\{{ }^{1} \mathrm{H}\right\}$ NMR spectrum of cyclohexylphosphorimidoyl trichloride S13

Figure S3. ${ }^{1} \mathrm{H}$ NMR spectrum of tris(cyclohexyl(methyl)amino)(cyclohexylamino)phosphonium hexafluorophosphate(V)

Figure S4. ${ }^{31} \mathrm{P}\left\{{ }^{1} \mathrm{H}\right\}$ NMR spectrum of tris(cyclohexyl(methyl)amino)(cyclohexylamino)phosphonium hexafluorophosphate(V) 
Figure S5. ${ }^{13} \mathrm{C}$ NMR spectrum of tris(cyclohexyl(methyl)amino)(cyclohexylamino)phosphonium hexafluorophosphate(V)

Figure S6. ${ }^{1} \mathrm{H}$ NMR spectrum of (cyclohexyl(4-vinylbenzyl)amino) tris(cyclohexyl(methyl)amino)phosphonium hexafluorophosphate(V).

Figure S7. ${ }^{31} \mathrm{P}\left\{{ }^{1} \mathrm{H}\right\}$ NMR spectrum of (cyclohexyl(4-vinylbenzyl)amino)

tris(cyclohexyl(methyl)amino)phosphonium hexafluorophosphate(V).

Figure S8. ${ }^{13} \mathrm{C}$ NMR spectrum of (cyclohexyl(4-vinylbenzyl)amino)

tris(cyclohexyl(methyl)amino)phosphonium hexafluorophosphate(V).

Figure S9. ${ }^{31} \mathrm{P}\left\{{ }^{1} \mathrm{H}\right\} \mathrm{NMR}$ spectrum of (cyclohexyl(4-

vinylbenzyl)amino)tris(cyclohexyl(methyl)amino)phosphonium

bis((trifluoromethyl)sulfonyl)amide

Figure S10. ${ }^{19}$ F NMR spectrum of (cyclohexyl(4-

vinylbenzyl)amino)tris(cyclohexyl(methyl)amino)phosphonium

bis((trifluoromethyl)sulfonyl)amide

Figure S11. ${ }^{1} \mathrm{H}$ NMR spectrum in DMSO- $d_{6}$ of copolymer (Table S1, entry b) .... S18

Figure S12. ${ }^{31} \mathrm{P}\left\{{ }^{1} \mathrm{H}\right\}$ NMR spectrum in DMSO- $d_{6}$ of copolymer (Table S1, entry b) .. S18

Figure S13. ${ }^{1} \mathrm{H}$ NMR spectrum in $\mathrm{CDCl}_{3}$ of polyisoprene-block-(Poly $\left(\mathbf{1}\left[\mathrm{PF}_{6}\right]\right.$-ran-

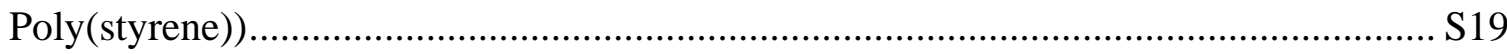

Kinetic Data S20

Figure S14. Representative Stacked ${ }^{1} \mathrm{H}$ NMR spectra ......................................... S20

Table S1. RAFT polymerization conditions of 1 with styrene …............................. S20

Table S2-S9. Kinetic data for polymerizations S21-S23

Figure S15. Kinetic plots of $\ln \left([\mathrm{M}]_{\mathrm{o}} /[\mathrm{M}]\right)$ versus time. S24

GPC Traces S25

Figure S16-S23. GPC traces for Table S1 polymerizations S25-S27

Figure S24. GPC overlay of chain extension polymerization................................ S28

TGA Curves . S29

Figure S25. TGA curves for Table S1 polymerizations. S29 
DSC Curves

Figure S26. DSC overlay for Table S1 polymerizations .......................................... S30

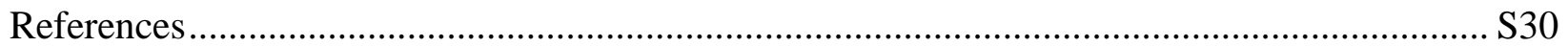


Materials and Methods. All reactions and manipulations of compounds were carried out in air unless otherwise specified. Toluene was purchased from Fischer Scientific and was degassed with argon and dried using a JCMeyer solvent system prior to use. All other solvents were purchased from Fischer Scientific and were used as received. $\mathrm{CDCl}_{3}$ was purchased from Cambridge Isotope Laboratories (CIL) and used as received. All reagents were purchased from commercial sources and used as received unless otherwise specified.

NMR Analysis. All NMR spectra were recorded on either a $300 \mathrm{MHz}$ or a $500 \mathrm{MHz}$ Bruker Avance Spectrometer. The ${ }^{31} \mathrm{P}\left\{{ }^{1} \mathrm{H}\right\}$ NMR spectra were referenced to an external standard (85\% $\mathrm{H}_{3} \mathrm{PO}_{4}$ ). The ${ }^{1} \mathrm{H}$ NMR spectra were reference to residual protio solvents $\left(7.24\right.$ for $\mathrm{CHCl}_{3}$ and 2.50 for DMSO- $d_{5}$ ) and ${ }^{13} \mathrm{C}$ NMR were referenced to $\mathrm{CDCl}_{3}$ (77.23 ppm).

High Resolution Electrospray Ionization Mass Spectrometry. High Resolution Electrospray Mass Spectrometry (ESI-MS) was performed in the School of Chemical Sciences Mass Spectrometry Laboratory at the University of Illinois, Urbana-Champaign.

Gel Permeation Chromatography. GPC measurements were performed on a Waters 2690 separations module apparatus equipped with two SDV columns (Porosity 1000 and $100000 \AA$; Polymer Standard Services) and a Waters 2414 Refractive Index detector. THF doped with 10 $\mathrm{mM} \mathrm{LiNTf}{ }_{2}$ was used as the eluent (flow rate $1 \mathrm{~mL} / \mathrm{min}, 40{ }^{\circ} \mathrm{C}$ ). A 9-point calibration based on polystyrene standards (Poly(styrene)) ReadyCal Kit, Polymer Standard Services) was applied for determination of molecular weights.

Thermal Gravimetric Analysis. TGA was ran using a Perkin Elmer Pyris under a nitrogen atmosphere starting from $25^{\circ} \mathrm{C}$ and ending at $500^{\circ} \mathrm{C}$ with a rate of $10{ }^{\circ} \mathrm{C} /$ minute. 
Differential Scanning Calorimetry. DSC analysis was performed on a Seiko SSC/5200 SII DSC220C Calorimeter using a scan range of $0-200{ }^{\circ} \mathrm{C}$ at a rate of $10^{\circ} \mathrm{C} /$ min under a nitrogen atmosphere for 3 cycles.

Kinetic Experiments. Conversion was measured by ${ }^{1} \mathrm{H}$ NMR spectroscopy ( $45^{\circ}$ tip, delay time $=10 \mathrm{~s})$ and measured as follows. After automatic phase adjustment and baseline correction using a $3^{\text {rd }}$ order Berstein polynomial fit, the area from $3.65-4.0 \mathrm{ppm}$ (anisole) was integrated and set to 1 . The area from $6.00-5.60 \mathrm{ppm}$ was integrated and compared between successive time points. This area corresponds to both vinyl protons for styrene and phosphonium monomer $\mathbf{1}$, therefore total monomer conversion was plotted. A plot of $\ln \left([\mathrm{M}]_{0} /[\mathrm{M}]\right)$ versus time was obtained from the calculated conversions.

$\% 1$ incorporation in the polymer. The amount of ionic content in the polymer was estimated using ${ }^{1} \mathrm{H}$ NMR spectroscopy and calculated as follows. The area $\left(\mathrm{A}_{1}\right)$ from $3.90-4.50 \mathrm{ppm}$ was integrated and set to 2 ( 2 benzylic protons from 1). The area $\left(A_{2}\right)$ from $6.00-7.50$ was integrated and the $\% \mathbf{1}$ composition was determined from the equation:

$$
\% \mathbf{1}=\frac{\left(\frac{A 1}{2}\right)}{\left(\frac{A 1}{2}\right)+\left[\left(A_{2}-4\right) / 5\right]} \times 100
$$




\section{Experimental Procedures}

\section{Scheme S1. Phosphonium Monomer Synthesis}

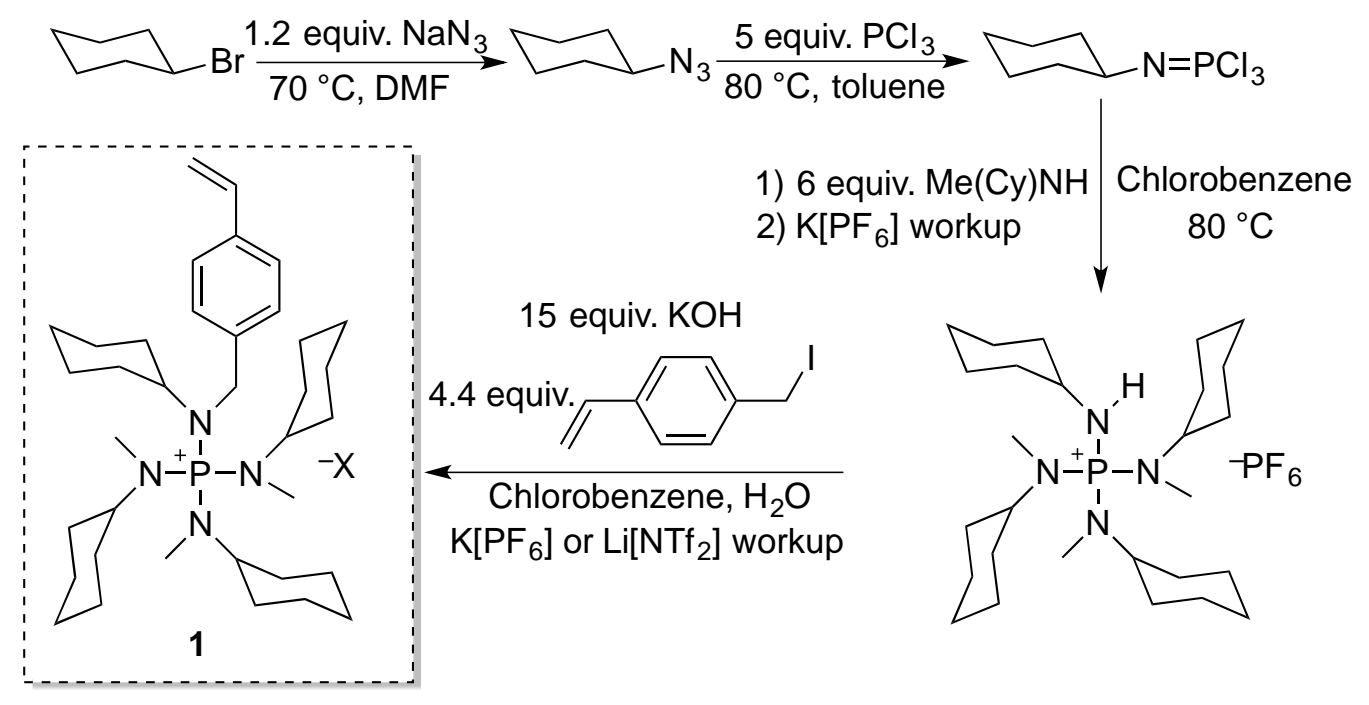

Preparation of azidocyclohexane. This compound was prepared according to a previous report. ${ }^{1}$ Bromocyclohexane $(36.3 \mathrm{~mL}, 294 \mathrm{mmol})$, sodium azide $(23.0 \mathrm{~g}$, $354 \mathrm{mmol}$ ) and DMF (300 mL) were combined in a three-necked round bottom flask under a nitrogen atmosphere. The flask was immersed in a $70{ }^{\circ} \mathrm{C}$ oil bath and stirred for $16 \mathrm{~h}$ (Caution: This experiment has been repeated multiple times and no explosion has occurred but a blast shield was used as a precaution). The reaction mixture was cooled to room temperature and diluted with $300 \mathrm{~mL}$ of water and $300 \mathrm{~mL}$ of diethyl ether. The mixture was transferred to a separatory funnel and the layers were separated. The aqueous layer was extracted twice with diethyl ether $(100 \mathrm{~mL})$. The organic extracts were combined and washed five times with water $(150 \mathrm{~mL})$. The organic layer was dried over $\mathrm{Na}_{2} \mathrm{SO}_{4}$, concentrated using rotary evaporation and a light brown oil was obtained (24.9 g, 68\% yield). ${ }^{1} \mathrm{H}$ NMR was consistent with the previous report and the product was used without further purification. 
Preparation of cyclohexylphosphorimidoyl trichloride. A $500 \mathrm{~mL}$

Schlenk bomb was evacuated and backfilled with nitrogen using standard

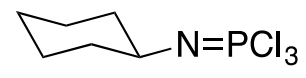

Schlenk techniques. Dry, degassed toluene $(75 \mathrm{~mL})$ and cyclohexyl azide $(24.0 \mathrm{~g}, 192 \mathrm{mmol})$ were added to the reaction vessel and stirred for 10 minutes. Phosphorus trichloride $(83.0 \mathrm{~mL}$, 949 mmol) was slowly added to the vessel by syringe and the mixture was stirred for 15 minutes. The flask was then immersed in an $80{ }^{\circ} \mathrm{C}$ oil bath and stirred for 30 minutes before sealing the vessel and the mixture was stirred overnight (Caution: This experiment has been repeated multiple times and no explosion has occurred but a blast shield was used as a precaution). The flask was cooled to room temperature, vented, and an aliquot was removed and analyzed using ${ }^{31} \mathrm{P}\left\{{ }^{1} \mathrm{H}\right\}$ NMR spectroscopy. A signal at $-74 \mathrm{ppm}$ in the ${ }^{31} \mathrm{P}\left\{{ }^{1} \mathrm{H}\right\}$ NMR spectrum confirmed formation of the desired compound. Excess $\mathrm{PCl}_{3}$ and toluene were removed in vacuo and the resultant red-brown oil was distilled using short path distillation path $\left(59{ }^{\circ} \mathrm{C}, 400\right.$ mtorr). The distilled product was a colorless oil (22.9 g, 51\% yield) and was used immediately in subsequent reactions because it tends to dimerize at room temperature. It can be stored for longer periods at $-40{ }^{\circ} \mathrm{C} .{ }^{31} \mathrm{P}\left\{{ }^{1} \mathrm{H}\right\}$ NMR $\left(202 \mathrm{MHz}, \mathrm{CDCl}_{3}\right) \delta-62.7 .{ }^{1} \mathrm{H} \mathrm{NMR}\left(500 \mathrm{MHz}, \mathrm{CDCl}_{3}\right) \delta 3.50-3.34$ $(\mathrm{m}, 1 \mathrm{H}), 1.90(\mathrm{dq}, J=12.1,3.8 \mathrm{~Hz}, 2 \mathrm{H}), 1.71(\mathrm{ddt}, J=13.4,6.4,3.0 \mathrm{~Hz}, 2 \mathrm{H}), 1.54(\mathrm{dt}, J=12.6$, $4.0 \mathrm{~Hz}, 1 \mathrm{H}), 1.44-1.33(\mathrm{~m}, 2 \mathrm{H}), 1.32-1.11(\mathrm{~m}, 3 \mathrm{H})$.

Preparation of tris(cyclohexyl(methyl)amino)(cyclohexylamino)phosphonium hexafluorophosphate(V). A $1000 \mathrm{~mL}$ three-necked round bottom flask was evacuated and backfilled with nitrogen using standard Schlenk techniques. Chlorobenzene $(70 \mathrm{~mL})$ and cyclohexylphosphorimidoyl trichloride $(27.33 \mathrm{~g}, 117 \mathrm{mmol})$ were combined in the reaction flask.

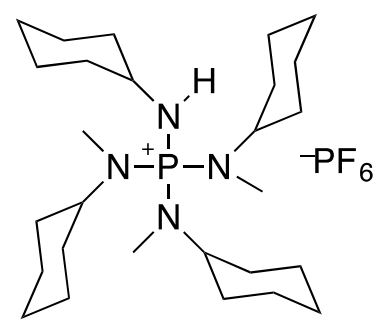
The flask was cooled to $0{ }^{\circ} \mathrm{C}$ using an ice bath and $\mathrm{N}$-methylcyclohexylamine $(91.6 \mathrm{~mL}, 702$ 
mmol) was slowly added to the reaction mixture and gas evolution was observed. After stirring for 30 minutes at $0{ }^{\circ} \mathrm{C}$, the flask was placed in an oil bath and heated to $80{ }^{\circ} \mathrm{C}$ and stirred overnight. An aliquot was removed from the reaction mixture and analyzed using ${ }^{31} \mathrm{P}\left\{{ }^{1} \mathrm{H}\right\} \mathrm{NMR}$ spectroscopy and a signal near $38 \mathrm{ppm}$ was observed which corresponded to the desired product. Upon completion, the flask was cooled to room temperature and the reaction mixture was diluted with $100 \mathrm{~mL}$ water and $100 \mathrm{~mL}$ dichloromethane. The organic layer was separated and the aqueous layer was washed with dichloromethane $(3 \times 50 \mathrm{~mL})$. The combined organic extracts were washed with water $(2 \times 100 \mathrm{~mL})$, a saturated aqueous solution of potassium hexafluorophosphate $(2 \times 100 \mathrm{~mL})$, and again with water $(1 \times 100 \mathrm{~mL})$. The organic phase was dried over $\mathrm{Na}_{2} \mathrm{SO}_{4}$, concentrated using rotary evaporation and the resultant oil was precipitated into a large volume of diethyl ether. The precipitate was collected using vacuum filtration and the white solid was dried in vacuo $\left(39.38 \mathrm{~g}, 55 \%\right.$ yield). ${ }^{31} \mathrm{P}\left\{{ }^{1} \mathrm{H}\right\} \mathrm{NMR}\left(121 \mathrm{MHz}, \mathrm{CDCl}_{3}\right) \delta$ $38.4(\mathrm{~s}, 1 \mathrm{P}),-144.2\left(\mathrm{sep}, J_{\mathrm{PF}}=713.9 \mathrm{~Hz}, 1 \mathrm{P}\right) .{ }^{1} \mathrm{H} \mathrm{NMR}\left(500 \mathrm{MHz}, \mathrm{CDCl}_{3}\right) \delta 3.87(\mathrm{dd}, J=12.7$, $10.3 \mathrm{~Hz}, 1 \mathrm{H}), 3.24-3.08(\mathrm{~m}, 3 \mathrm{H}), 2.76-2.66(\mathrm{~m}, 1 \mathrm{H}), 2.62(\mathrm{~d}, J=9.9 \mathrm{~Hz}, 9 \mathrm{H}), 1.88-1.71(\mathrm{~m}$, $10 \mathrm{H}), 1.69-1.49(\mathrm{~m}, 18 \mathrm{H}), 1.38-1.23(\mathrm{~m}, 6 \mathrm{H}), 1.21-1.11(\mathrm{~m}, 3 \mathrm{H}), 1.10-0.97(\mathrm{~m}, 3 \mathrm{H}) .{ }^{13} \mathrm{C}$ $\operatorname{NMR}\left(126 \mathrm{MHz}, \mathrm{CDCl}_{3}\right) \delta 55.6\left(\mathrm{~d}, J_{\mathrm{PC}}=5.3 \mathrm{~Hz}\right), 52.2,35.1\left(\mathrm{~d}, J_{\mathrm{PC}}=4.3 \mathrm{~Hz}\right), 30.7\left(\mathrm{~d}, J_{\mathrm{PC}}=2.8\right.$ $\mathrm{Hz}), 29.6\left(\mathrm{~d}, J_{\mathrm{PC}}=4.1 \mathrm{~Hz}\right), 26.0,25.4,24.9$. Note: only 8 of the 9 possible signals from the cyclohexyl substituents are visible due to similarities between chemical environments. HRMS (ESI-TOF) (m/z): [M] $]^{+}$calculated for $\mathrm{C}_{27} \mathrm{H}_{54} \mathrm{~N}_{4} \mathrm{P}^{+}$: 465.4081 ; found 465.4077 .

Preparation of 1-(iodomethyl)-4-vinylbenzene. 1-(chloromethyl)-4vinylbenzene was converted into the title compound using a modified literature procedure. ${ }^{2}$ Acetone $(200 \mathrm{~mL}), 1$-(chloromethyl)-4-vinylbenzene $(7.1 \mathrm{~mL}, 50 \mathrm{mmol})$, and potassium iodide $(25.0 \mathrm{~g}, 150 \mathrm{mmol})$ were combined in a $500 \mathrm{~mL}$ round-bottom flask. The 
flask was covered to minimize light exposure and stirred overnight. The solvent was removed by rotary evaporation and the crude product was combined with water $(200 \mathrm{~mL})$ and diethyl ether $(200 \mathrm{~mL})$. The organic layer was separated and the aqueous layer was extracted 3 more times with ether $(50 \mathrm{~mL})$. The organic extracts were combined and washed with a saturated solution of sodium thiosulfate $(3 \times 100 \mathrm{~mL})$ and $100 \mathrm{~mL}$ water. The organic extracts were dried using $\mathrm{Na}_{2} \mathrm{SO}_{4}$, concentrated using rotary evaporation, and a yellow oil was obtained (11.24 g, 92\%

yield). ${ }^{1} \mathrm{H}$ NMR spectrum was consistent with the previous report and the compound was used without further purification.

Preparation

of

(cyclohexyl(4vinylbenzyl)amino)tris(cyclohexyl(methyl)amino)phosphonium hexafluorophosphate(V) (1[PF $\mathbf{1}])$. Tris(cyclohexyl(methyl)amino)(cyclohexylamino)phosphonium hexafluorophosphate(V) (4.00 g, $6.5 \mathrm{mmol})$, chlorobenzene $(6 \mathrm{~mL}), 11.0$ $\mathrm{g}$ aqueous $\mathrm{KOH}$ solution (50/50, w/w) and 1-(iodomethyl)-4vinylbenzene $(7.00 \mathrm{~g}, 28.6 \mathrm{mmol})$ were combined in a $50 \mathrm{~mL}$ roundbottom flask. The flask was covered to minimize light exposure and stirred at room temperature overnight. Aliquots were removed from the

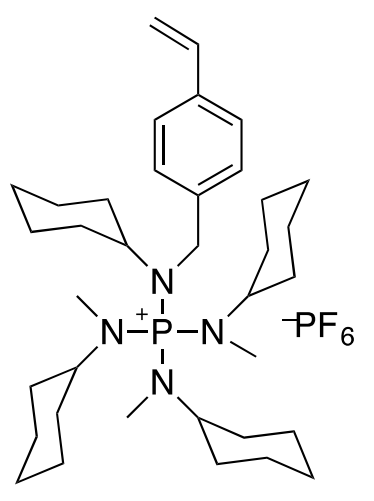
reaction mixture and analyzed using ${ }^{31} \mathrm{P}\left\{{ }^{1} \mathrm{H}\right\}$ NMR spectroscopy to monitor the disappearance of the starting material and to confirm formation of the product near $48 \mathrm{ppm}$. Upon completion, the reaction mixture was diluted with $50 \mathrm{~mL}$ water and $50 \mathrm{~mL}$ dichloromethane. The mixture was transferred to a separatory funnel and the layers were separated. The aqueous layer was extracted once more with dichloromethane and the combined organic extracts were washed twice with a saturated aqueous solution of potassium hexafluorophosphate $(50 \mathrm{~mL})$, and once with water $(50$ 
$\mathrm{mL}$ ). The organic layer was dried over $\mathrm{Na}_{2} \mathrm{SO}_{4}$ and concentrated by rotary evaporation. The yellow oil was precipitated into $150 \mathrm{~mL}$ diethyl ether. The solid was collected using vacuum filtration and washed with diethyl ether $(3 \times 50 \mathrm{~mL})$. The compound was redissolved in a minimum amount of dichloromethane and precipitated into diethyl ether twice more. The product was obtained as a white solid (4.1 g, 86\% yield). $\delta^{31} \mathrm{P}\left\{{ }^{1} \mathrm{H}\right\} \mathrm{NMR}\left(202 \mathrm{MHz}, \mathrm{CDCl}_{3}\right) \delta$ 48.5 (s, 1P), -143.4 (sep, $\left.J_{\mathrm{PF}}=712.2,1 \mathrm{P}\right) .{ }^{1} \mathrm{H}$ NMR $\left(300 \mathrm{MHz}, \mathrm{CDCl}_{3}\right) \delta 7.38(\mathrm{~d}, J=8.2 \mathrm{~Hz}$, 2H), $7.24(\mathrm{~d}, J=8.2 \mathrm{~Hz}, 2 \mathrm{H}), 6.69(\mathrm{dd}, J=17.6,10.9 \mathrm{~Hz}, 1 \mathrm{H}), 5.76(\mathrm{~d}, J=17.7 \mathrm{~Hz}, 1 \mathrm{H}), 5.27$ $(\mathrm{d}, J=11.0 \mathrm{~Hz}, 1 \mathrm{H}), 4.32(\mathrm{~d}, J=10.2 \mathrm{~Hz}, 2 \mathrm{H}), 3.31-3.01(\mathrm{~m}, 4 \mathrm{H}), 2.65(\mathrm{~d}, J=9.9 \mathrm{~Hz}, 9 \mathrm{H})$, $1.91(\mathrm{~d}, J=11.9 \mathrm{~Hz}, 6 \mathrm{H}), 1.85-1.50(\mathrm{~m}, 20 \mathrm{H}), 1.50-1.00(\mathrm{~m}, 13 \mathrm{H}), 0.99-0.81(\mathrm{~m}, 1 \mathrm{H}) .{ }^{13} \mathrm{C}$ NMR $\left(126 \mathrm{MHz}, \mathrm{CDCl}_{3}\right) \delta 137.5,137.3\left(\mathrm{~d}, J_{\mathrm{PC}}=5.4 \mathrm{~Hz}\right), 136.2,127.8,126.7,114.7,59.5(\mathrm{~d}$, $\left.J_{\mathrm{PC}}=3.8 \mathrm{~Hz}\right), 56.3\left(\mathrm{~d}, J_{\mathrm{PC}}=4.4 \mathrm{~Hz}\right), 48.2\left(\mathrm{~d}, J_{\mathrm{PC}}=4.6 \mathrm{~Hz}\right), 33.2\left(\mathrm{~d}, J_{\mathrm{PC}}=3.1 \mathrm{~Hz}\right), 30.7\left(\mathrm{~d}, J_{\mathrm{PC}}=\right.$ $2.7 \mathrm{~Hz}), 30.4\left(\mathrm{~d}, J_{\mathrm{PC}}=3.8 \mathrm{~Hz}\right), 26.9,26.1,25.2,25.1$. HRMS (ESI-TOF) $(\mathrm{m} / \mathrm{z}):[\mathrm{M}]^{+}$for $\mathrm{C}_{36} \mathrm{H}_{62} \mathrm{~N}_{4} \mathrm{P}^{+}$: calculated 581.4707; found 581.4705.

Anion metathesis for phosphonium monomer. $5.0 \mathrm{~g}$ of $\mathbf{1}\left[\mathbf{P F}_{\mathbf{6}}\right]$ was dissolved in $150 \mathrm{~mL}$ of dichloromethane. The mixture was washed with a saturated solution of $\left.\mathrm{Li}_{[\mathrm{NTf}}\right](3 \times 50 \mathrm{~mL})$. Anion exchange could be monitored using ${ }^{19} \mathrm{~F}$ and ${ }^{31} \mathrm{P}\left\{{ }^{1} \mathrm{H}\right\}$ NMR spectroscopy (Final spectra shown in Figures S9 and S10). After full conversion to the ${ }^{-}\left[\mathrm{NTf}_{2}\right]$ counterion, the organic layer was washed with water, dried over $\mathrm{Na}_{2} \mathrm{SO}_{4}$ and concentrated using rotary evaporation. 


\section{Scheme S2. RAFT Copolymerization of Styrene and 1}

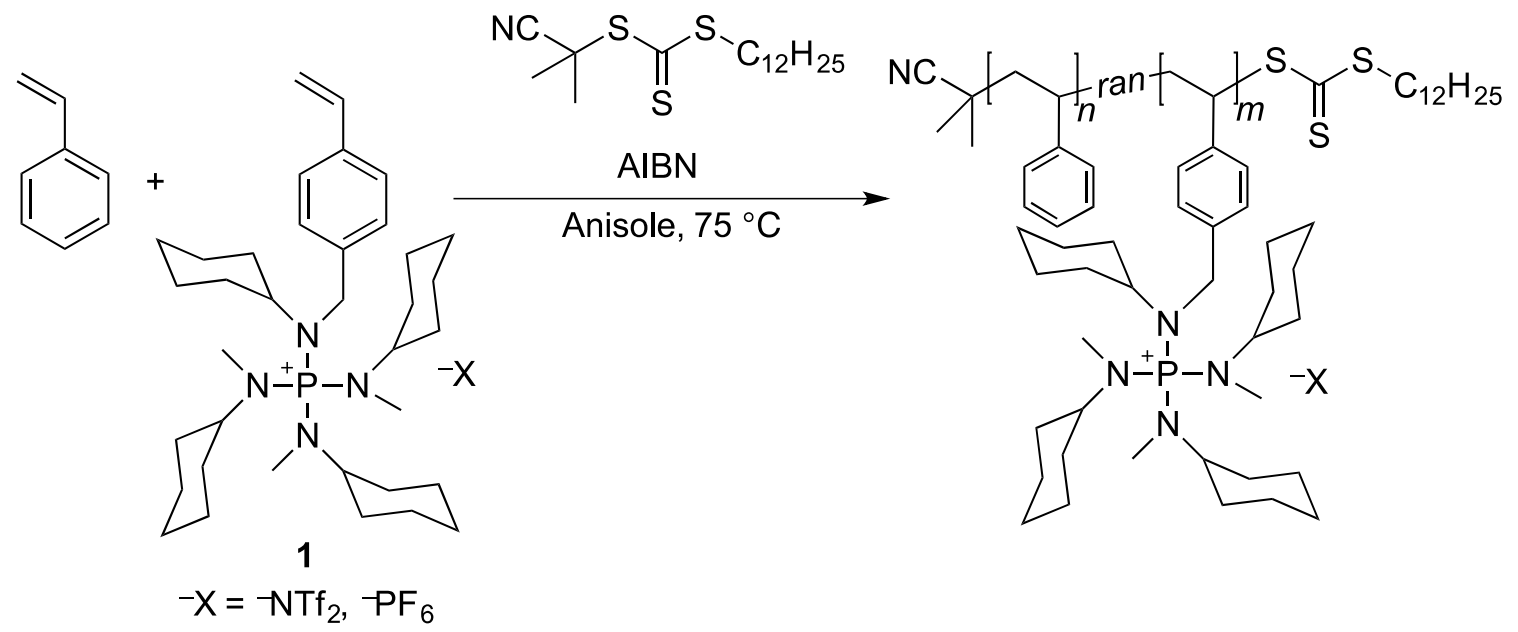

General RAFT Polymerization of Polyelectrolyte copolymers. Phosphonium monomer 1, styrene, the RAFT agent (2-cyano-2-propyl dodecyl trithiocarbonate) and anisole were added to a $10 \mathrm{~mL}$ Schlenk flask (monomer and solvent amounts are included in Table S1). Reactions were typically conducted at total monomer concentrations of $5 \mathrm{M}$. The flask was degassed by three freeze-pump-thaw cycles. While the contents of the flask were frozen, AIBN was added and the flask was evacuated and backfilled with nitrogen three more times. The flask was then submerged in a $75{ }^{\circ} \mathrm{C}$ oil bath. Samples were taken periodically via syringe and analyzed by ${ }^{1} \mathrm{H}$ NMR to measure percent conversion. Exposing the contents of the flask to air stopped the polymerizations. The polymers were precipitated into methanol and filtered to yield off-white powders.

Preparation of Polyisoprene-block-(Poly(1[PF $])$-ran-Poly(styrene)). Polyisoprene macroRAFT agent was prepared according to a modified literature report using 2-cyano-2-propyl dodecyl trithiocarbonate as the chain transfer agent. ${ }^{3}$ In a $10 \mathrm{~mL}$ Schlenk flask, styrene $(0.91$ $\mathrm{mL}), \mathbf{1}\left[\mathbf{P F}_{\mathbf{6}}\right](0.80 \mathrm{~g})$, and the macro-RAFT agent $\left(0.22 \mathrm{~g}, M_{\mathrm{n}}=10100, Ð=1.23\right)$ were added to $2.2 \mathrm{~mL}$ anisole. The contents were subjected to three consecutive freeze-pump-thaw cycles. 
While the contents of the flask were frozen, AIBN ( $2 \mathrm{mg}$ ) was added and the flask was evacuated and backfilled with nitrogen three more times. The flask was then submerged in a $75^{\circ} \mathrm{C}$ oil bath. Exposing the contents of the flask to air stopped the polymerization. The polymer was precipitated into ethanol and filtered to yield a white powder $\left(M_{\mathrm{n}}=26000, \nexists=1.27\right)$. 


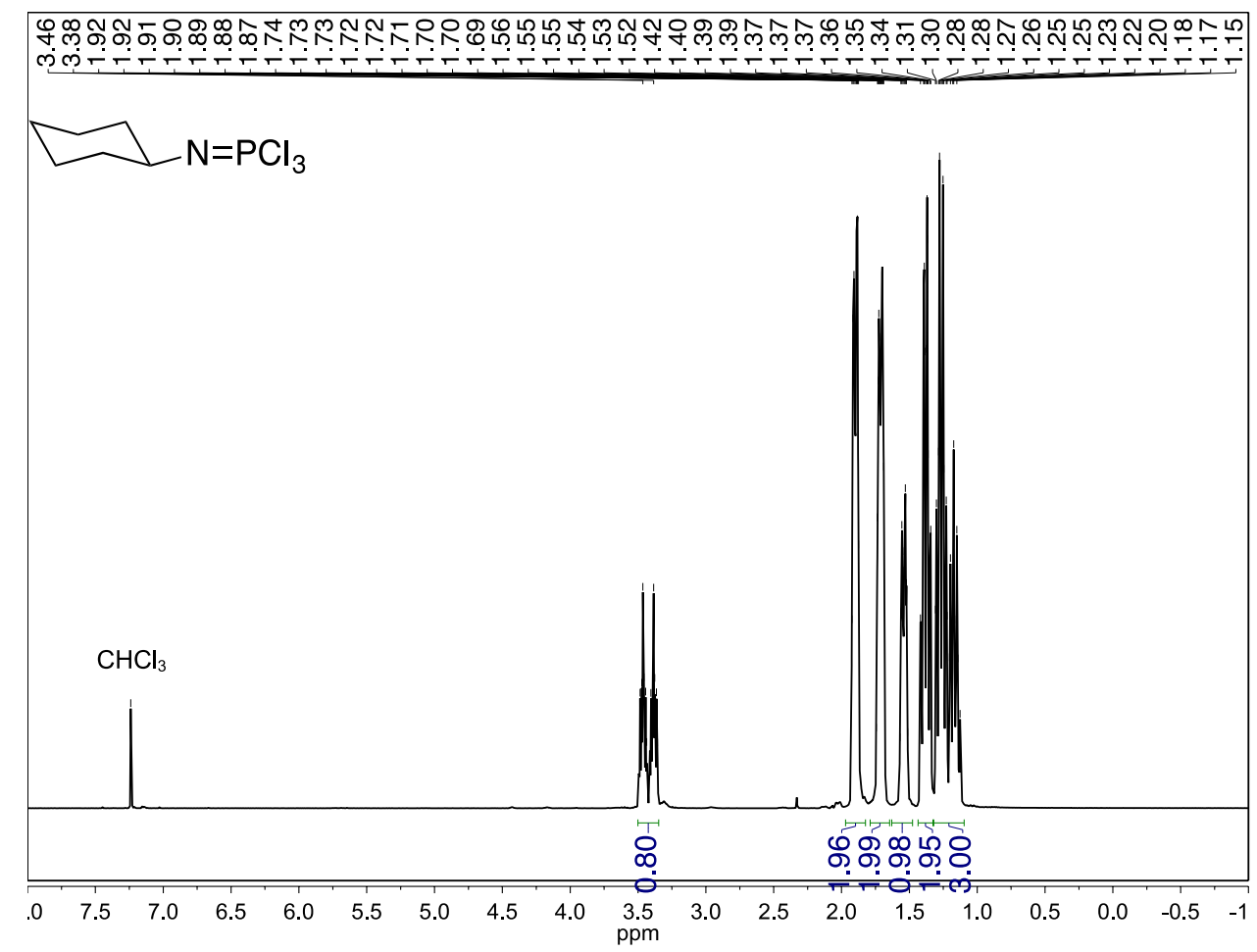

Figure S1. ${ }^{1} \mathrm{H}$ NMR spectrum in $\mathrm{CDCl}_{3}, 500 \mathrm{MHz}$.

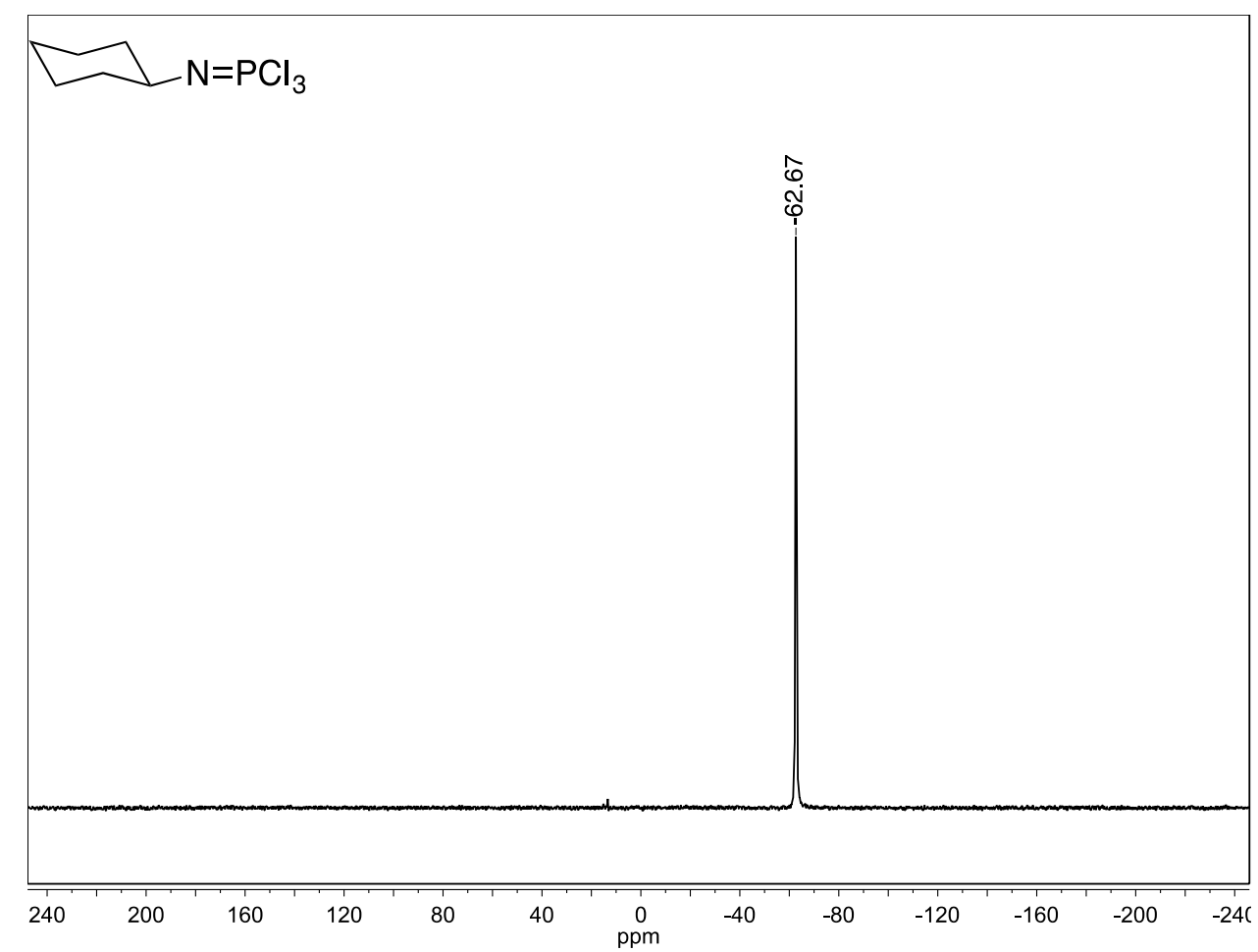

Figure S2. ${ }^{31} \mathrm{P}\left\{{ }^{1} \mathrm{H}\right\}$ NMR spectrum in $\mathrm{CDCl}_{3}, 202 \mathrm{MHz}$. 


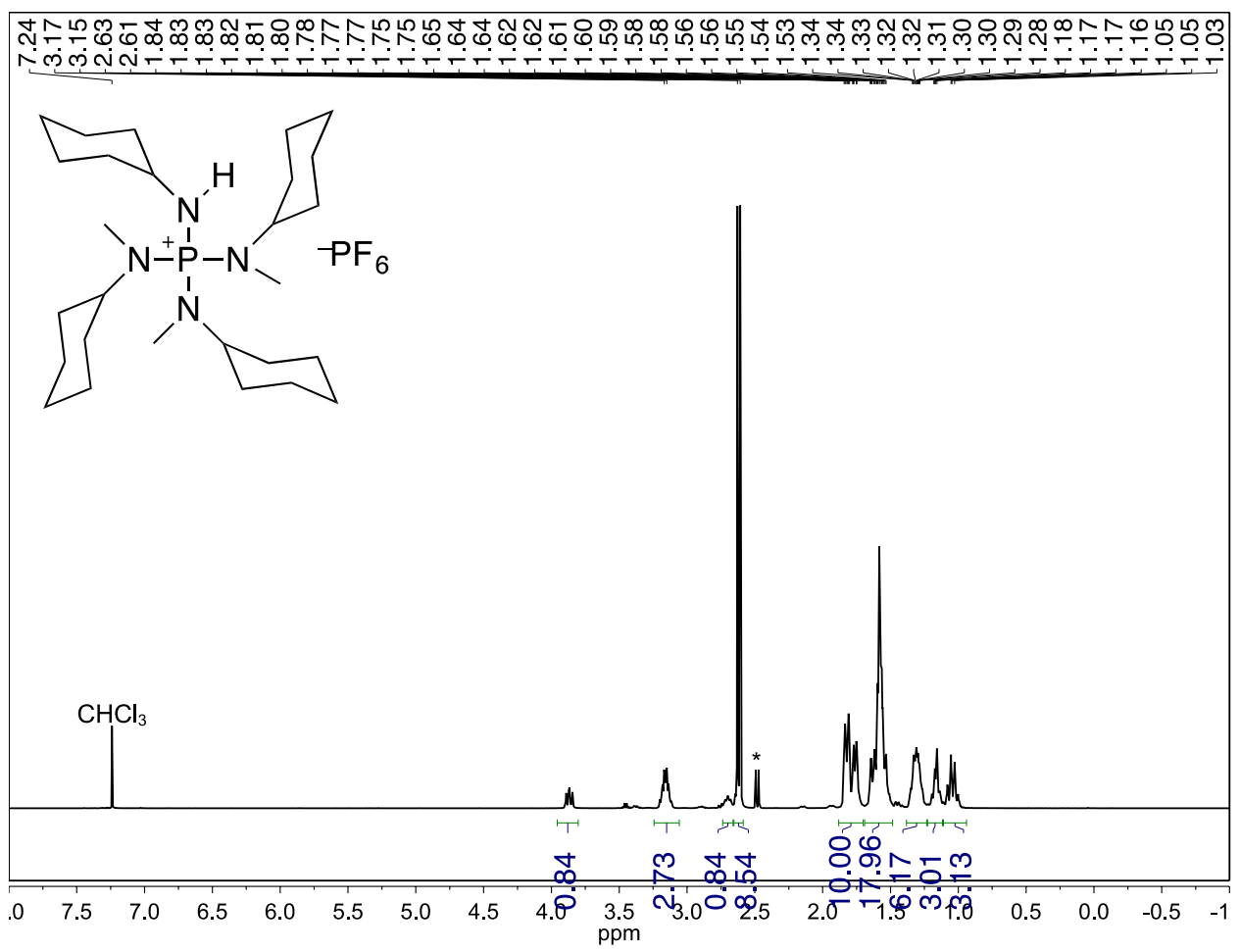

Figure S3. ${ }^{1} \mathrm{H}$ NMR spectrum in $\mathrm{CDCl}_{3}, 500 \mathrm{MHz}$.

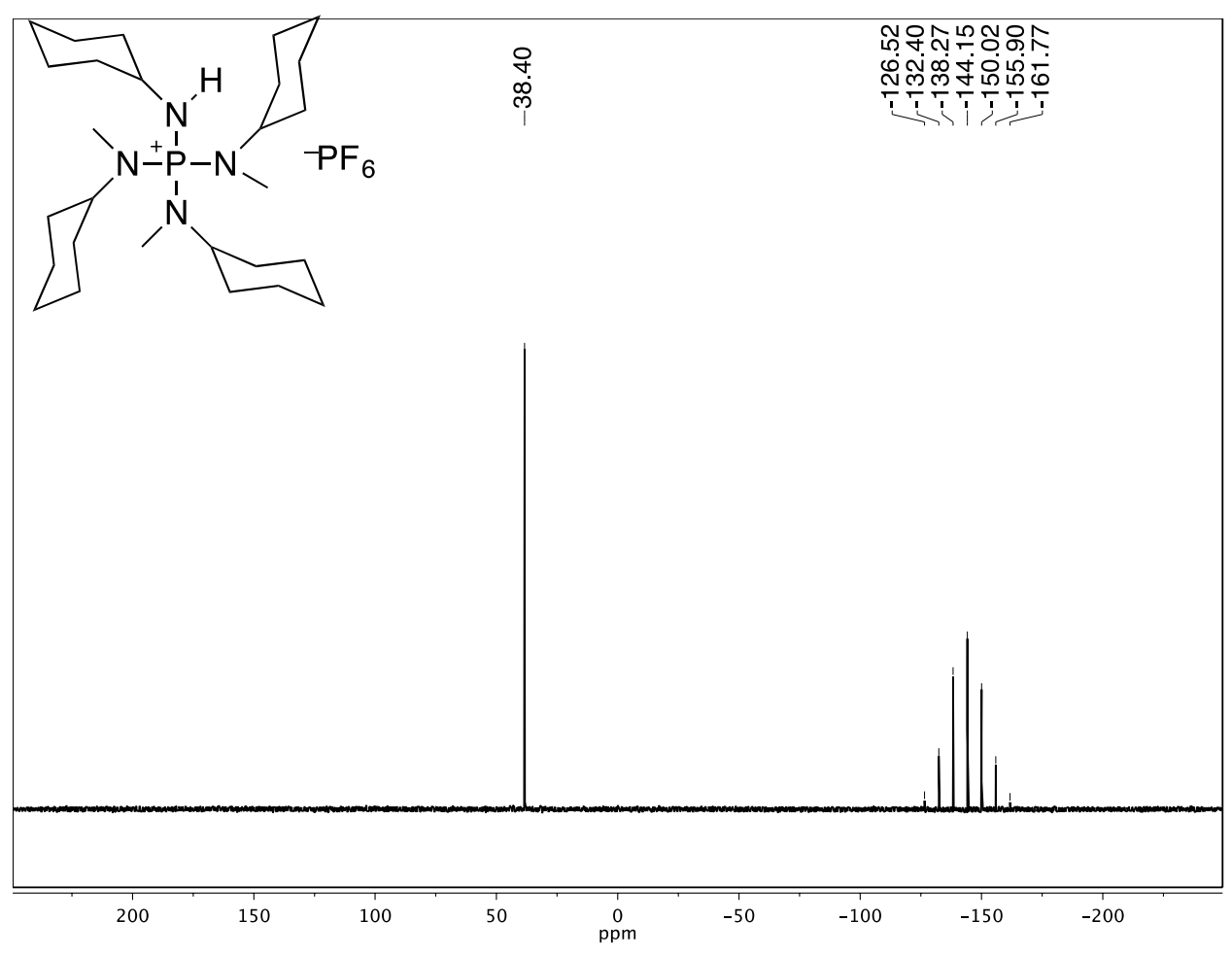

Figure S4. ${ }^{31} \mathrm{P}\left\{{ }^{1} \mathrm{H}\right\}$ NMR spectrum in $\mathrm{CDCl}_{3}, 121 \mathrm{MHz}$. 


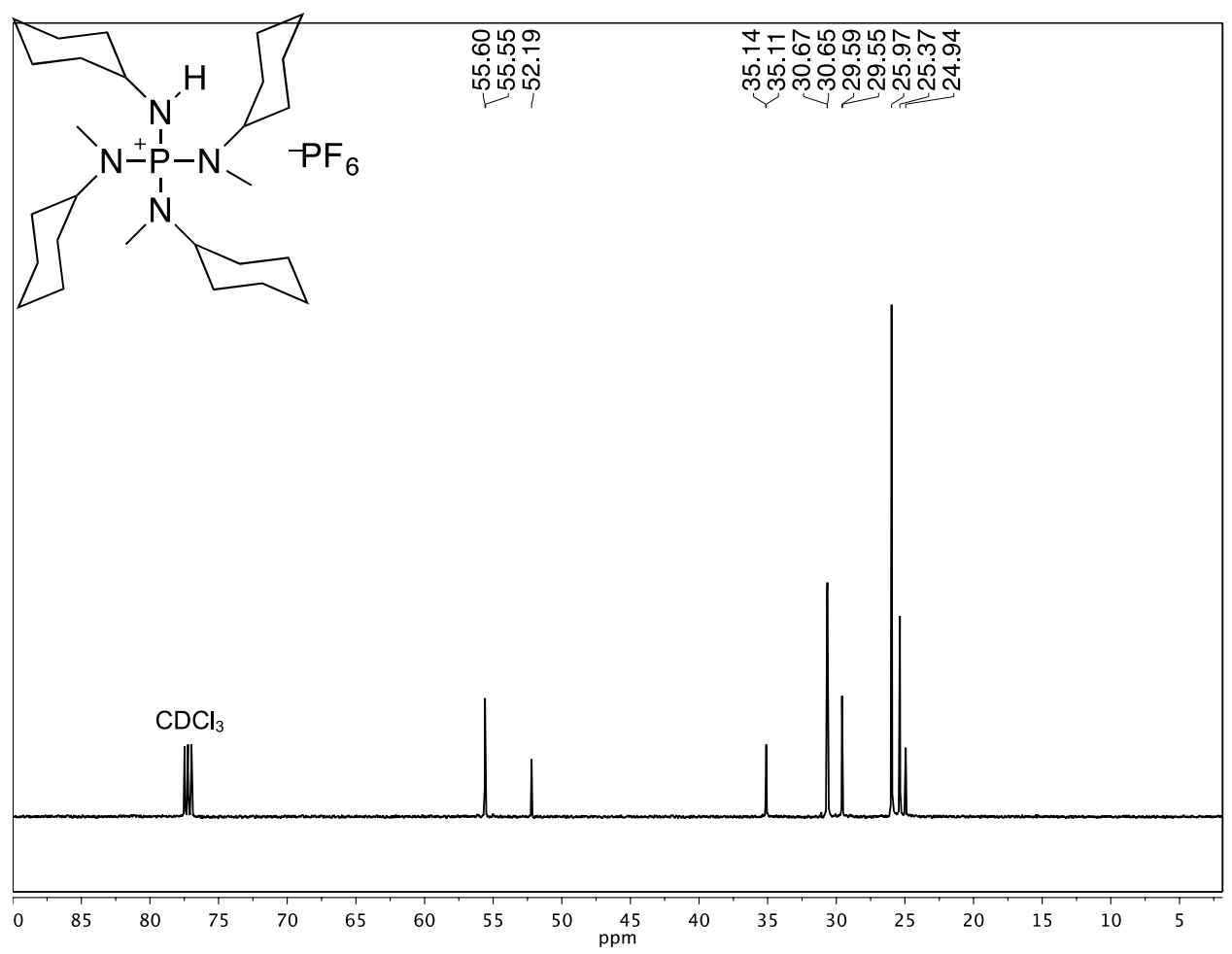

Figure S5. ${ }^{13} \mathrm{C}$ NMR spectrum in $\mathrm{CDCl}_{3}, 126 \mathrm{MHz}$.

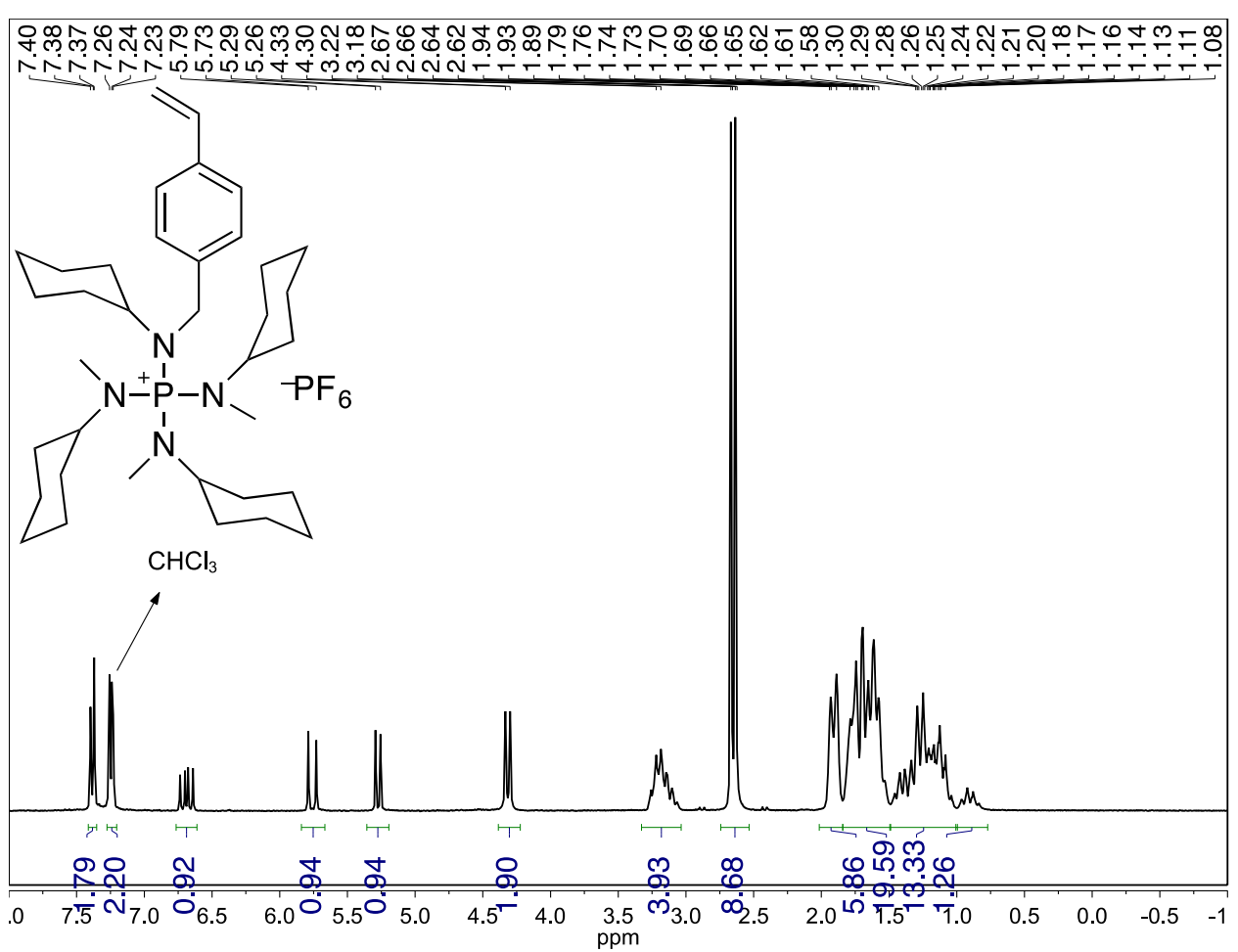

Figure S6. ${ }^{1} \mathrm{H}$ NMR spectrum in $\mathrm{CDCl}_{3}, 300 \mathrm{MHz}$. 


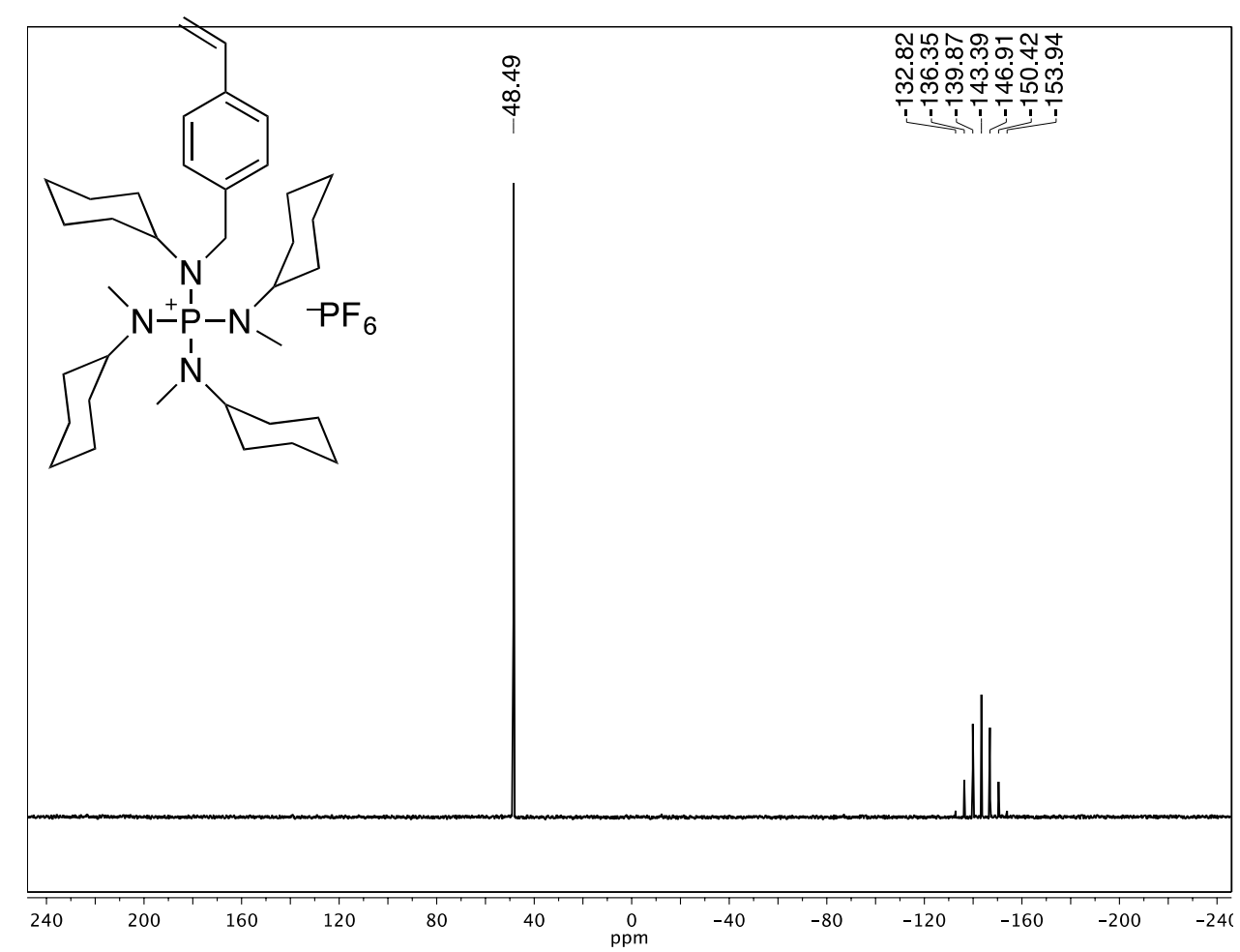

Figure S7. ${ }^{31} \mathrm{P}\left\{{ }^{1} \mathrm{H}\right\}$ NMR spectrum in $\mathrm{CDCl}_{3}, 202 \mathrm{MHz}$.

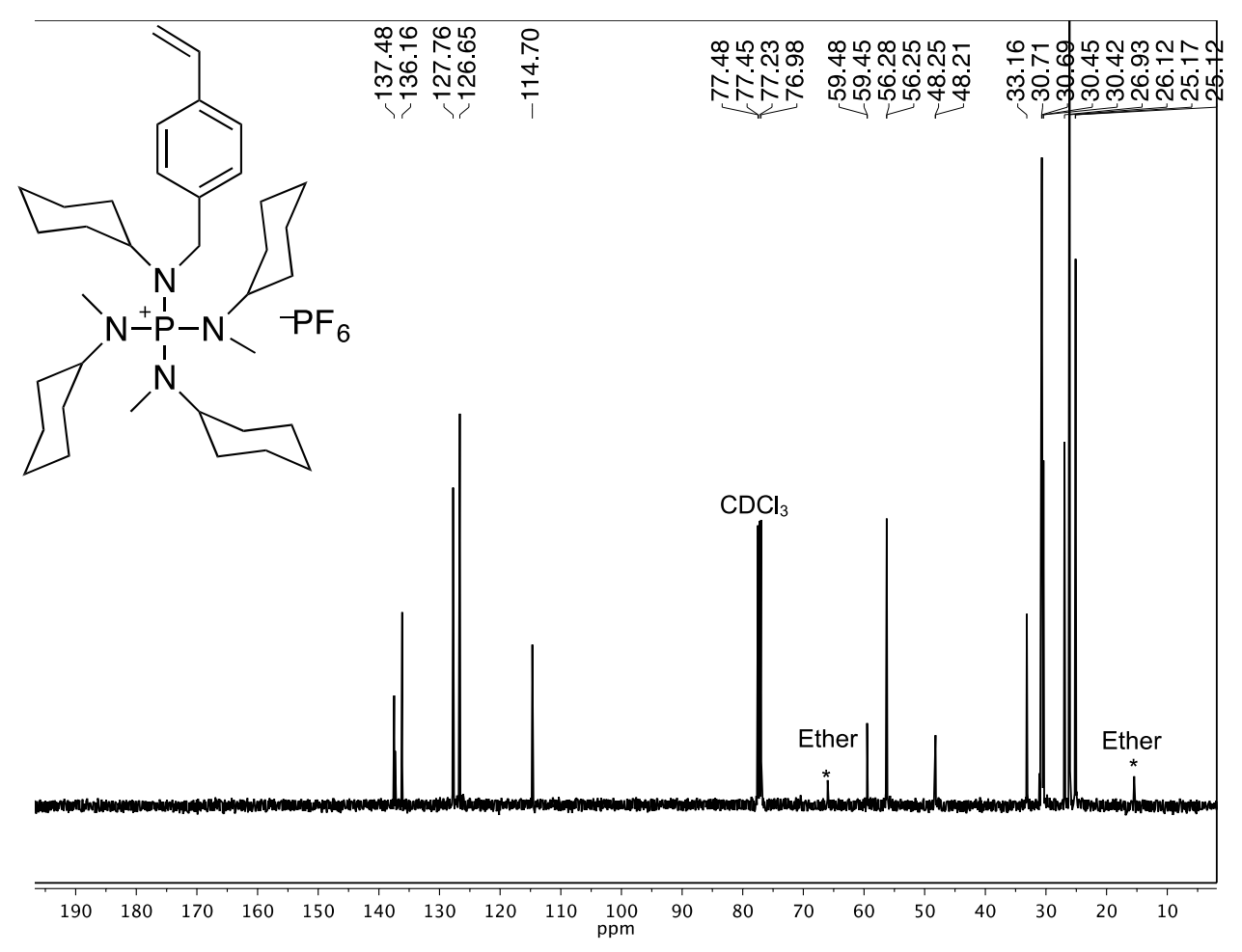

Figure S8. ${ }^{13} \mathrm{C}$ NMR spectrum in $\mathrm{CDCl}_{3}, 126 \mathrm{MHz}$. 


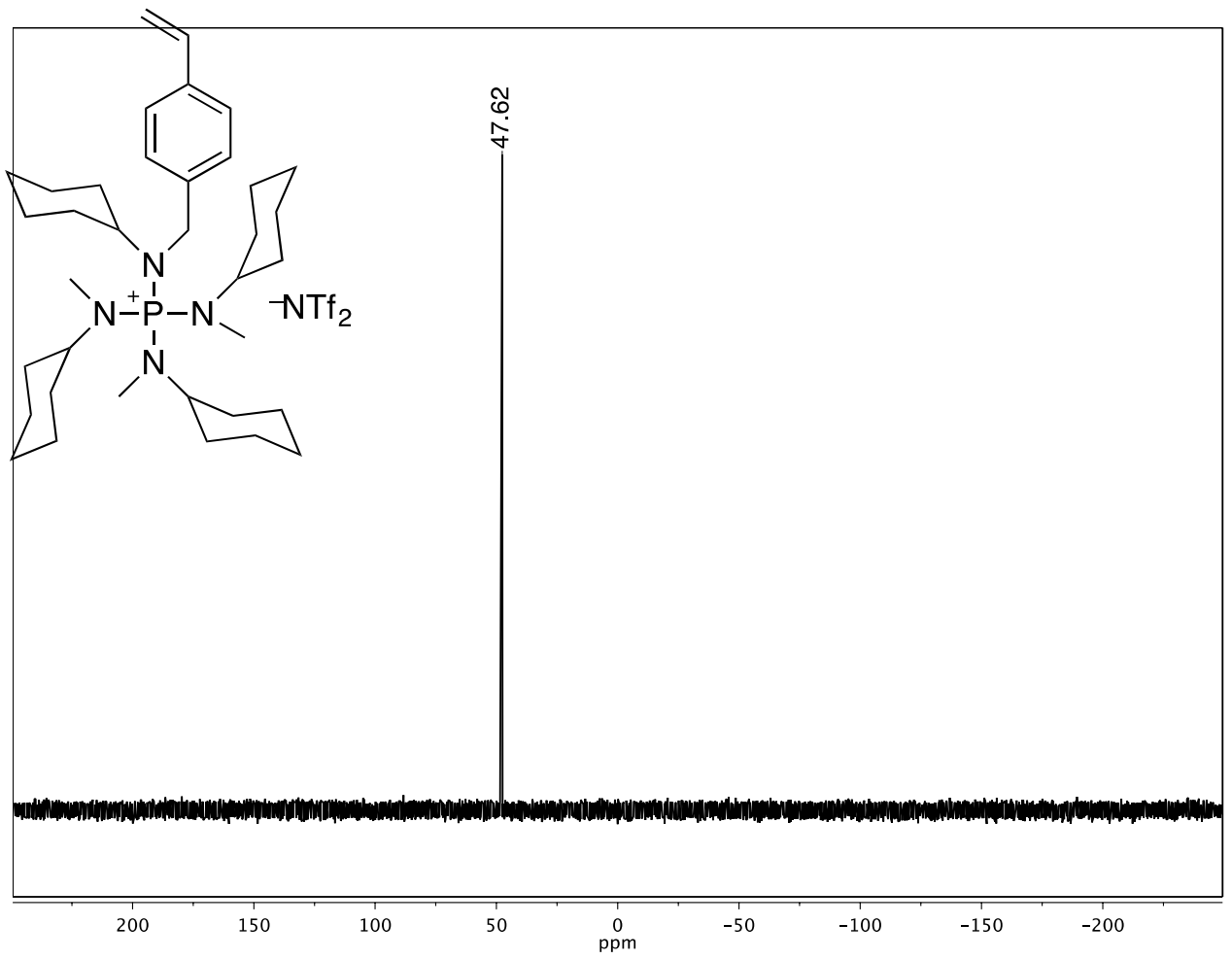

Figure S9. ${ }^{31} \mathrm{P}\left\{{ }^{1} \mathrm{H}\right\}$ NMR spectrum in $\mathrm{CDCl}_{3}$ (anion exchange), $121 \mathrm{MHz}$.

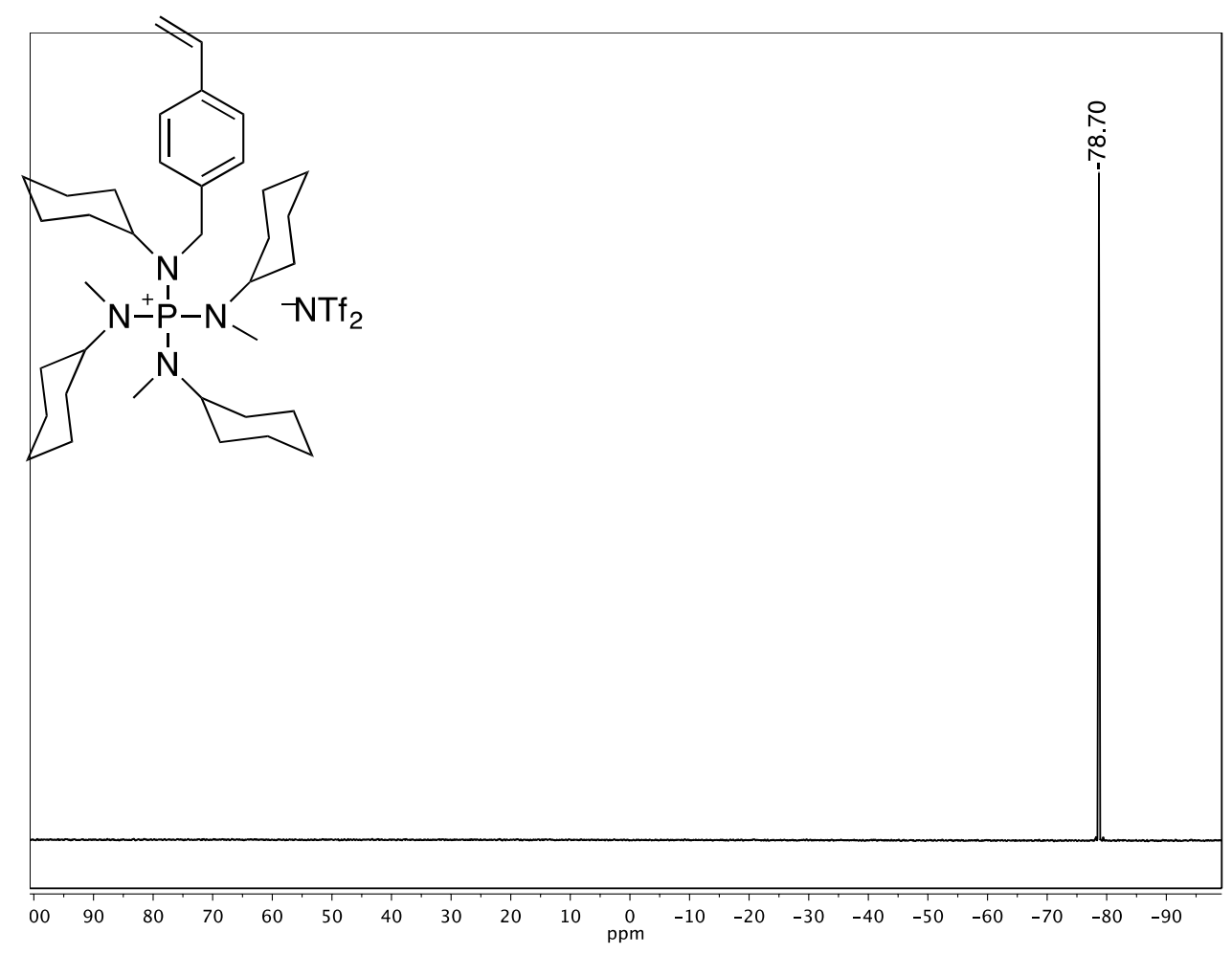

Figure S10. ${ }^{19} \mathrm{~F}$ NMR spectrum in $\mathrm{CDCl}_{3}$ (anion exchange), $282 \mathrm{MHz}$. 


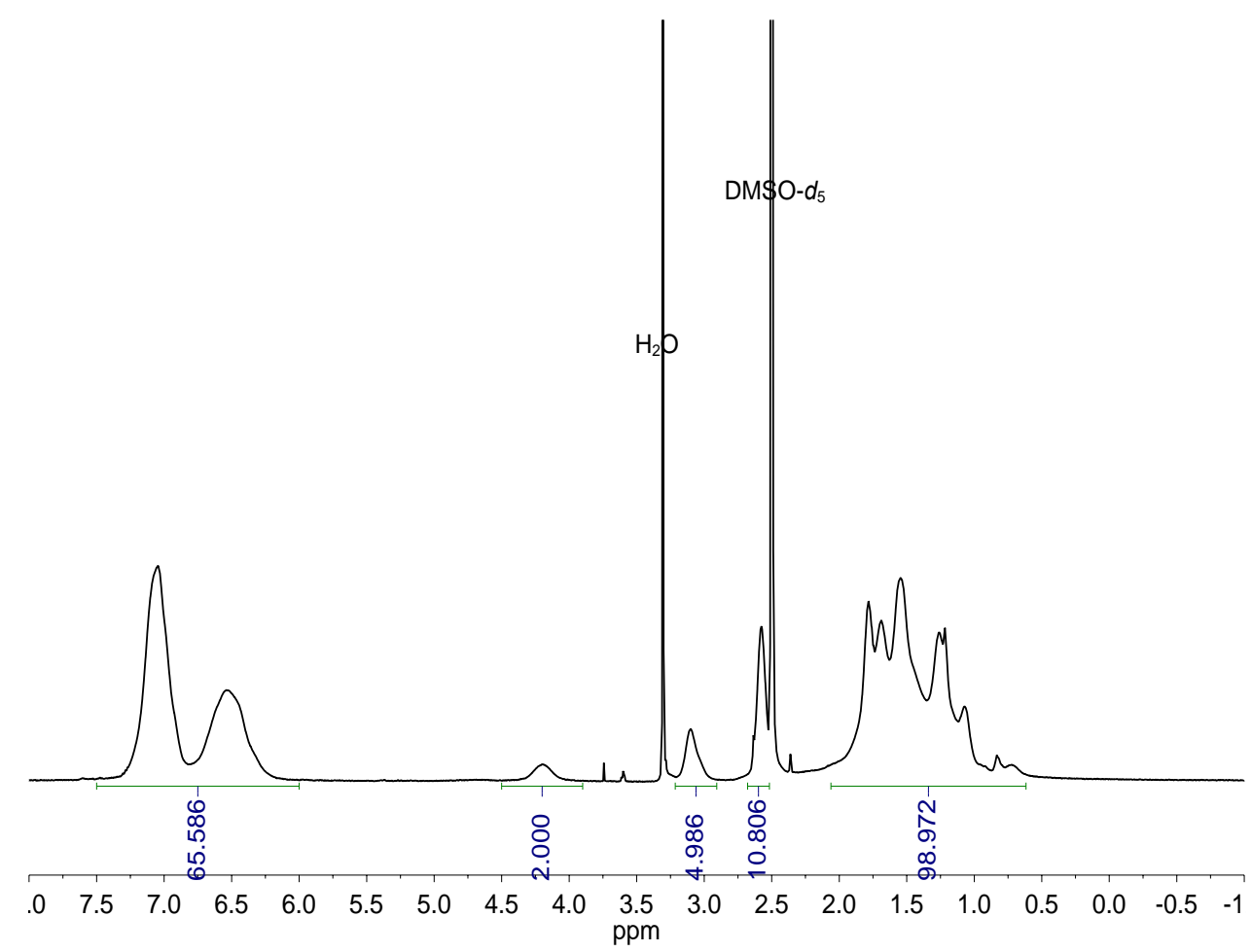

Figure S11. ${ }^{1} \mathrm{H}$ NMR spectrum in DMSO- $d_{6}$ of copolymer (Table S1, entry b), $500 \mathrm{MHz}$.

̊
ヘ่

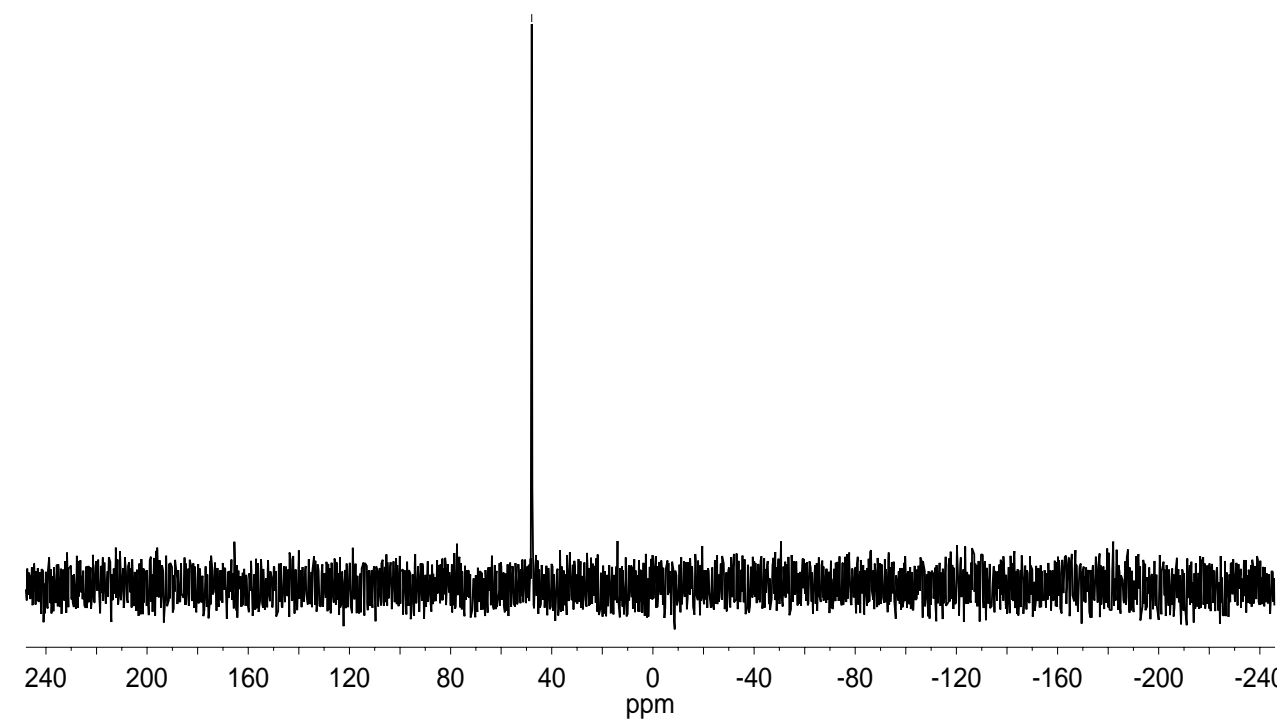

Figure S12. ${ }^{31} \mathrm{P}\left\{{ }^{1} \mathrm{H}\right\}$ NMR spectrum in DMSO- $d_{6}$ of copolymer (Table S1 entry b), $202 \mathrm{MHz}$. 


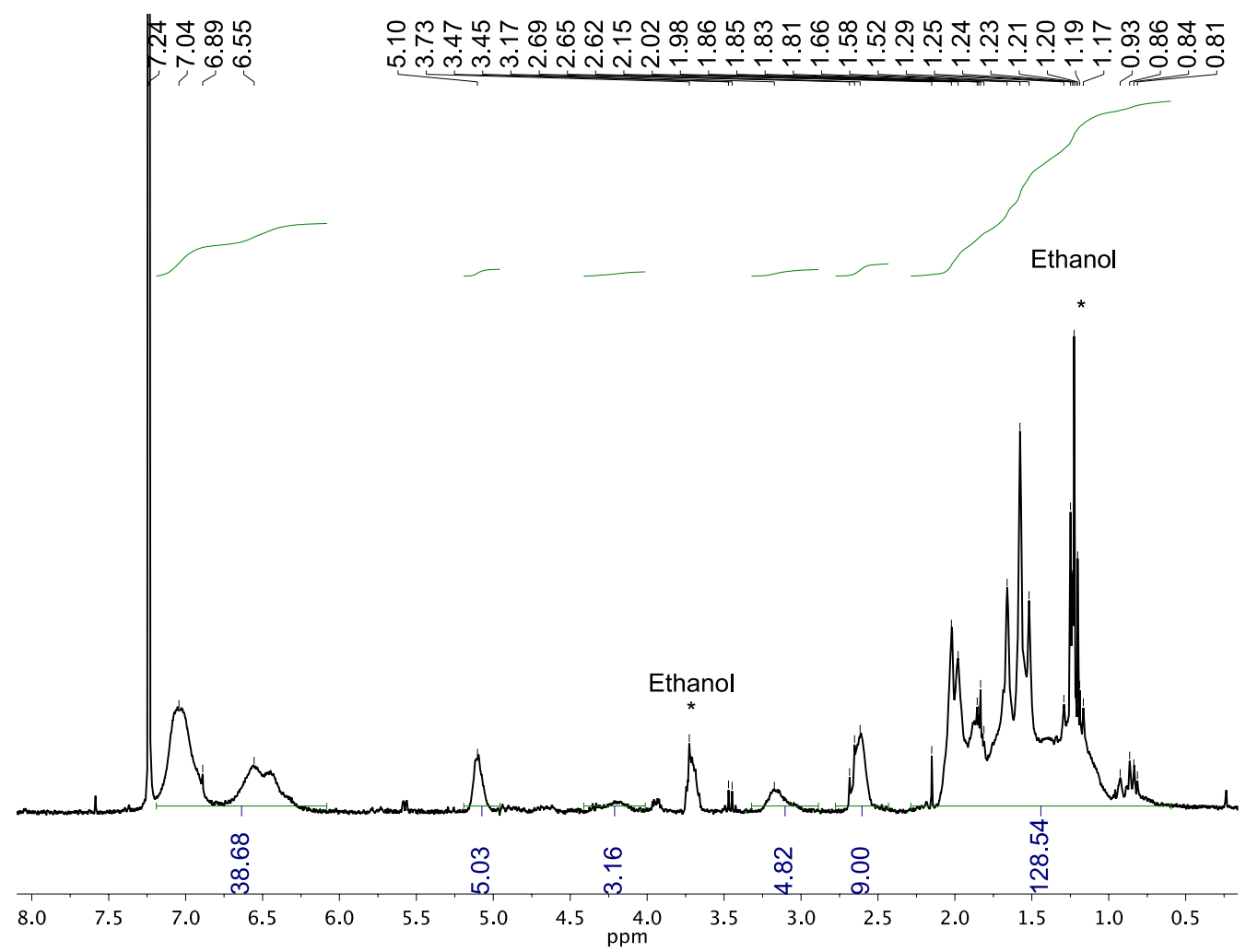

Figure S13. ${ }^{1} \mathrm{H}$ NMR spectrum of polyisoprene-block-(Poly $\left(\mathbf{1}\left[\mathrm{PF}_{6}\right]\right.$-ran-Poly(styrene $\left.)\right)$ in $\mathrm{CDCl}_{3}, 300 \mathrm{MHz}$. The different configurations of polyisoprene from radical polymerization afforded a relatively complicated ${ }^{1} \mathrm{H}$ NMR spectrum, particularly with the incorporation of monomer 1. The presence of some residual ethanol from precipitation affected the integration of the alkyl region. 


\section{Kinetic Data}

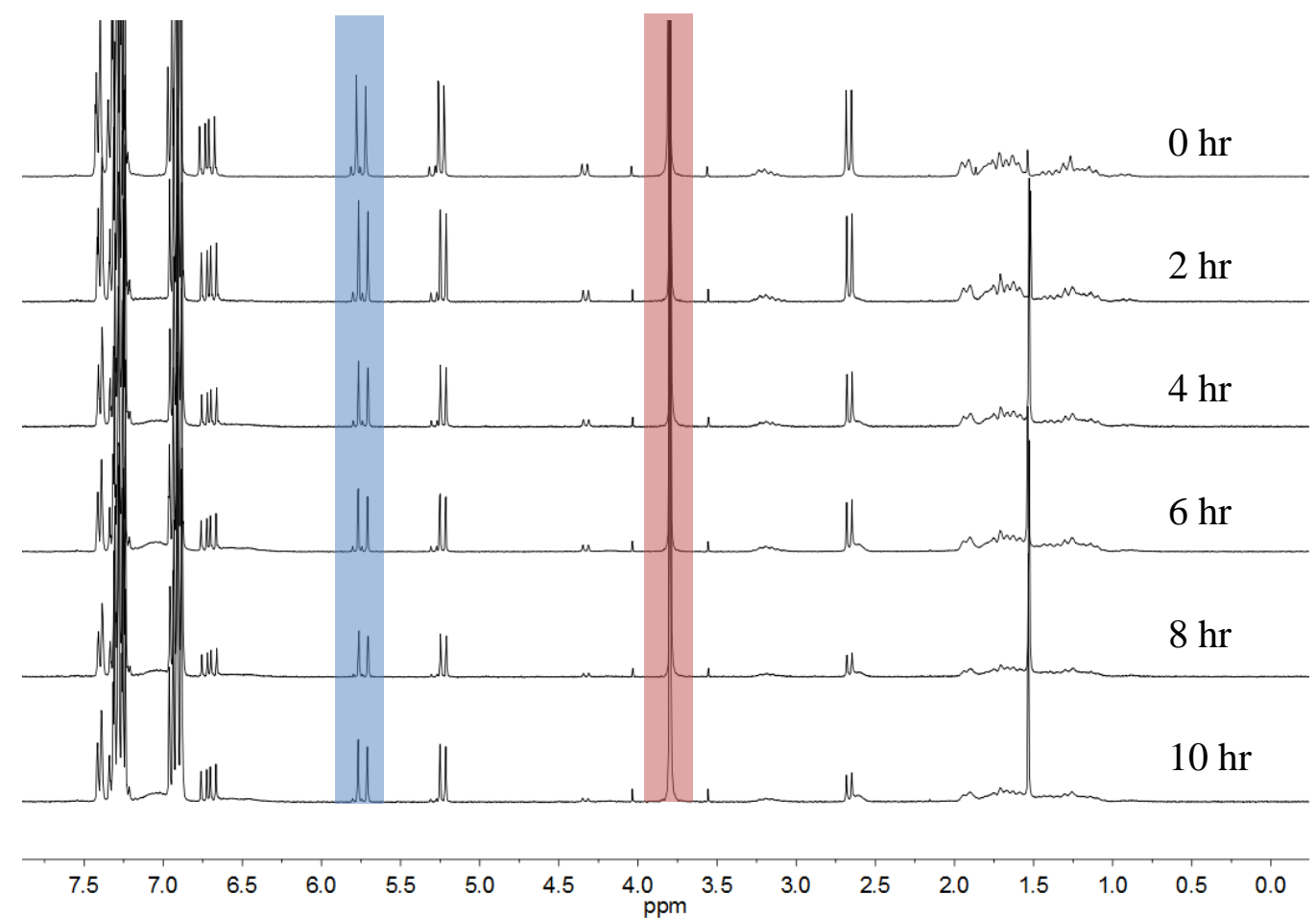

Figure S14. Representative Stacked ${ }^{1} \mathrm{H}$ NMR spectra of $0,2,4,6,8,10 \mathrm{~h}$ for copolymerization with 90:10 styrene:1[NTf ${ }_{2}$ ] and starting with 0.5 mol \% RAFT agent (Table S1, entry b). 300 $\mathrm{MHz}$.

Table S1. RAFT polymerization conditions of $\mathbf{1}$ with styrene.

\begin{tabular}{ccccccc}
\hline \multirow{2}{*}{ Entry } & $\begin{array}{c}\text { Mol \% } \\
\text { styrene/1/CPDTTC/AIBN }\end{array}$ & counterion & solvent & $\begin{array}{c}\text { Styrene } \\
(\mathrm{mL})\end{array}$ & $\begin{array}{c}\text { Phosphonium } \\
(\mathrm{g})\end{array}$ & $\begin{array}{c}\text { Anisole } \\
(\mathrm{mL})\end{array}$ \\
\hline $\mathrm{a}$ & $95 / 5 / 0.5 / 0.25$ & $-\mathrm{NTf}_{2}$ & anisole & 0.63 & 0.25 & 1.15 \\
$\mathrm{~b}$ & $90 / 10 / 0.5 / 0.25$ & $-\mathrm{NTf}_{2}$ & anisole & 1.18 & 1.01 & 2.30 \\
$\mathrm{c}$ & $85 / 15 / 0.5 / 0.25$ & $-\mathrm{NTf}_{2}$ & anisole & 0.75 & 1.02 & 1.54 \\
$\mathrm{~d}$ & $80 / 20 / 0.5 / 0.25$ & $-\mathrm{NTf}_{2}$ & anisole & 0.26 & 0.50 & 0.58 \\
$\mathrm{e}$ & $90 / 10 / 0.5 / 0.25$ & $-\mathrm{PF}_{6}$ & anisole & 0.71 & 0.50 & 1.37 \\
$\mathrm{f}$ & $85 / 15 / 0.5 / 0.25$ & $-\mathrm{PF}_{6}$ & anisole & 0.45 & 0.50 & 0.92 \\
$\mathrm{~g}$ & $90 / 10 / 0.2 / 0.1$ & $-\mathrm{NTf}_{2}$ & anisole & 0.59 & 0.50 & 1.15 \\
$\mathrm{~h}$ & $90 / 10 / 0.1 / 0.05$ & $-\mathrm{NTf}_{2}$ & anisole & 0.59 & 0.50 & 1.15 \\
\hline
\end{tabular}

Polymerizations were conducted at $75^{\circ} \mathrm{C}$ with a total monomer concentration $[\mathrm{M}]_{\text {total }}=5 \mathrm{M}$. 
Table S2. Kinetic data for 95:5 styrene: $\mathbf{1}\left[\mathbf{N T f _ { 2 }}\right.$ ] with $0.5 \mathrm{~mol} \%$ RAFT agent in anisole (Table S1, entry a)

\begin{tabular}{cccccc}
\hline Time & {$[\mathrm{M}]_{0}$} & $\begin{array}{c}\text { NMR } \\
\text { integral }\end{array}$ & conversion & {$[\mathrm{M}]$} & $\ln \left([\mathrm{M}]_{\mathrm{o}} /[\mathrm{M}]\right)$ \\
\hline 0 & 5.00 & 0.175 & 0.000 & 5.00 & 0.000 \\
120 & & 0.147 & 0.160 & 4.20 & 0.174 \\
240 & & 0.124 & 0.291 & 3.54 & 0.345 \\
360 & & 0.110 & 0.371 & 3.14 & 0.464 \\
480 & & 0.100 & 0.429 & 2.86 & 0.560 \\
600 & & 0.093 & 0.469 & 2.66 & 0.632 \\
\hline
\end{tabular}

Table S3. Kinetic data for 90:10 styrene: $\mathbf{1}\left[\mathbf{N T f _ { 2 }}\right.$ ] with 0.5 mol \% RAFT agent in anisole (Table S1, entry b)

\begin{tabular}{cccccc}
\hline Time & {$[\mathrm{M}]_{0}$} & $\begin{array}{c}\text { NMR } \\
\text { integral }\end{array}$ & conversion & {$[\mathrm{M}]$} & $\ln \left([\mathrm{M}]_{\mathrm{o}} /[\mathrm{M}]\right)$ \\
\hline 0 & 5.00 & 0.172 & 0.000 & 5.00 & 0.000 \\
120 & & 0.146 & 0.151 & 4.24 & 0.164 \\
240 & & 0.121 & 0.297 & 3.52 & 0.352 \\
360 & & 0.105 & 0.390 & 3.05 & 0.494 \\
480 & & 0.084 & 0.512 & 2.44 & 0.717 \\
600 & & 0.074 & 0.570 & 2.15 & 0.843 \\
\hline
\end{tabular}

Table S4. Kinetic data for 85:15 styrene: $\mathbf{1}\left[\mathbf{N T f}_{2}\right]$ with $0.5 \mathrm{~mol} \%$ RAFT agent in anisole (Table S1, entry c)

\begin{tabular}{cccccc}
\hline Time & {$[\mathrm{M}]_{\circ}$} & $\begin{array}{c}\text { NMR } \\
\text { integral }\end{array}$ & conversion & {$[\mathrm{M}]$} & $\ln \left([\mathrm{M}]_{\mathrm{o}} /[\mathrm{M}]\right)$ \\
\hline 0 & 5.00 & 0.174 & 0.000 & 5.00 & 0.000 \\
120 & & 0.146 & 0.161 & 4.20 & 0.175 \\
240 & & 0.116 & 0.333 & 3.33 & 0.405 \\
360 & & 0.096 & 0.448 & 2.76 & 0.595 \\
480 & & 0.082 & 0.529 & 2.36 & 0.752 \\
600 & & 0.074 & 0.575 & 2.13 & 0.855 \\
\hline
\end{tabular}


Table S5. Kinetic data for 80:20 styrene: $\mathbf{1}\left[\mathbf{N T f}_{2}\right]$ with $0.5 \mathrm{~mol} \%$ RAFT agent in anisole (Table S1, entry d)

\begin{tabular}{cccccc}
\hline Time & {$[\mathrm{M}] \mathrm{o}$} & $\begin{array}{c}\text { NMR } \\
\text { integral }\end{array}$ & conversion & {$[\mathrm{M}]$} & $\ln \left([\mathrm{M}]_{\mathrm{o}} /[\mathrm{M}]\right)$ \\
\hline 0 & 5.00 & 0.173 & 0.000 & 5.00 & 0.000 \\
120 & & 0.163 & 0.058 & 4.71 & 0.060 \\
240 & & 0.127 & 0.266 & 3.67 & 0.309 \\
360 & & 0.103 & 0.405 & 2.98 & 0.519 \\
480 & & 0.081 & 0.532 & 2.34 & 0.759 \\
600 & & 0.072 & 0.584 & 2.08 & 0.877 \\
\hline
\end{tabular}

Table S6. Kinetic data for 90:10 styrene: $\mathbf{1}\left[\mathbf{P F}_{\mathbf{6}}\right]$ with $0.5 \mathrm{~mol} \%$ RAFT agent in anisole (Table S1, entry e)

\begin{tabular}{cccccc}
\hline Time & {$[\mathrm{M}]_{\mathrm{o}}$} & $\begin{array}{c}\text { NMR } \\
\text { integral }\end{array}$ & conversion & {$[\mathrm{M}]$} & $\ln \left([\mathrm{M}]_{\mathrm{o}} /[\mathrm{M}]\right)$ \\
\hline 0 & 5.00 & 0.174 & 0.000 & 5.00 & 0.000 \\
120 & & 0.149 & 0.144 & 4.28 & 0.155 \\
240 & & 0.128 & 0.264 & 3.68 & 0.307 \\
360 & & 0.102 & 0.414 & 2.93 & 0.534 \\
480 & & 0.089 & 0.489 & 2.56 & 0.670 \\
\hline
\end{tabular}

Table S7. Kinetic data for 85:15 styrene: $\mathbf{1}\left[\mathbf{P F}_{\mathbf{6}}\right]$ with $0.5 \mathrm{~mol} \%$ RAFT agent in anisole (Table S1, entry f)

\begin{tabular}{cccccc}
\hline Time & {$[\mathrm{M}]_{\mathrm{o}}$} & $\begin{array}{c}\text { NMR } \\
\text { integral }\end{array}$ & conversion & {$[\mathrm{M}]$} & $\ln \left([\mathrm{M}]_{\mathrm{o}} /[\mathrm{M}]\right)$ \\
\hline 0 & 5.00 & 0.172 & 0.000 & 5.00 & 0.000 \\
120 & & 0.142 & 0.174 & 4.13 & 0.192 \\
240 & & 0.106 & 0.384 & 3.08 & 0.484 \\
360 & & 0.089 & 0.483 & 2.59 & 0.659 \\
480 & & 0.075 & 0.564 & 2.18 & 0.830 \\
\hline
\end{tabular}


Table S8. Kinetic data for 90:10 styrene: $\mathbf{1}\left[\mathbf{N T f}_{2}\right]$ with $0.2 \mathrm{~mol} \%$ RAFT agent in anisole (Table S1, entry g)

\begin{tabular}{cccccc}
\hline Time & {$[\mathrm{M}]_{0}$} & $\begin{array}{c}\text { NMR } \\
\text { integral }\end{array}$ & conversion & {$[\mathrm{M}]$} & $\ln \left([\mathrm{M}]_{\mathrm{o}} /[\mathrm{M}]\right)$ \\
\hline 0 & 5.00 & 0.173 & 0.000 & 5.00 & 0.000 \\
120 & & 0.169 & 0.023 & 4.88 & 0.023 \\
240 & & 0.152 & 0.121 & 4.39 & 0.129 \\
360 & & 0.137 & 0.208 & 3.96 & 0.233 \\
480 & & 0.119 & 0.312 & 3.44 & 0.374 \\
600 & & 0.117 & 0.324 & 3.38 & 0.391 \\
\hline
\end{tabular}

Table S9. Kinetic data for 90:10 styrene: $\mathbf{1}\left[\mathbf{N T f _ { 2 }}\right.$ ] with 0.1 mol \% RAFT agent in anisole (Table S1, entry h)

\begin{tabular}{cccccc}
\hline Time & {$[\mathrm{M}]_{0}$} & $\begin{array}{c}\text { NMR } \\
\text { integral }\end{array}$ & conversion & {$[\mathrm{M}]$} & $\ln \left([\mathrm{M}]_{\mathrm{o}} /[\mathrm{M}]\right)$ \\
\hline 0 & 5.00 & 0.172 & 0.000 & 5.00 & 0.000 \\
120 & & 0.165 & 0.041 & 4.80 & 0.042 \\
240 & & 0.148 & 0.140 & 4.30 & 0.150 \\
360 & & 0.134 & 0.221 & 3.90 & 0.250 \\
480 & & 0.12 & 0.302 & 3.49 & 0.360 \\
600 & & 0.116 & 0.326 & 3.37 & 0.394 \\
\hline
\end{tabular}


a)

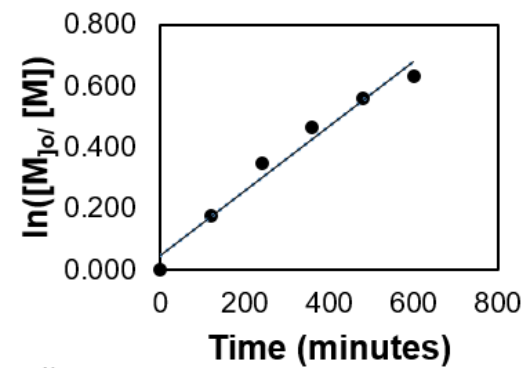

d)

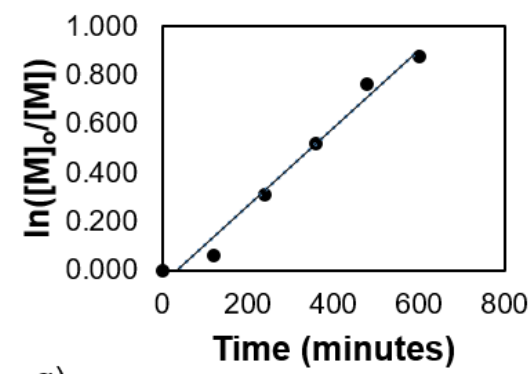

g)

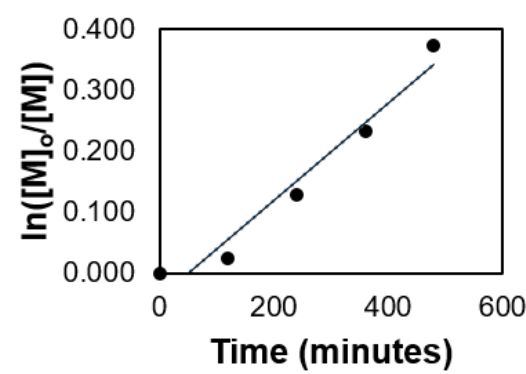

b)

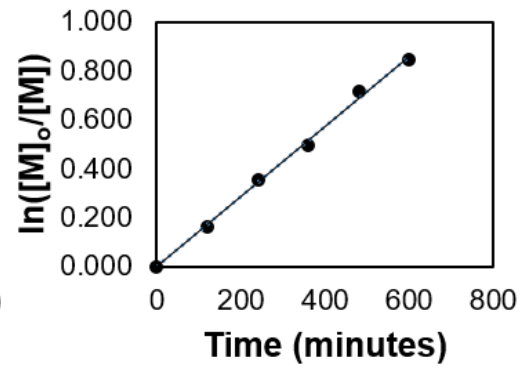

e)

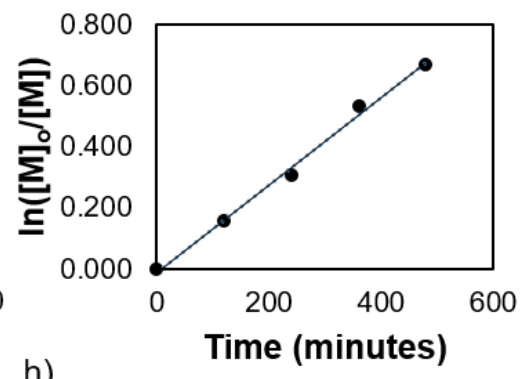

h)

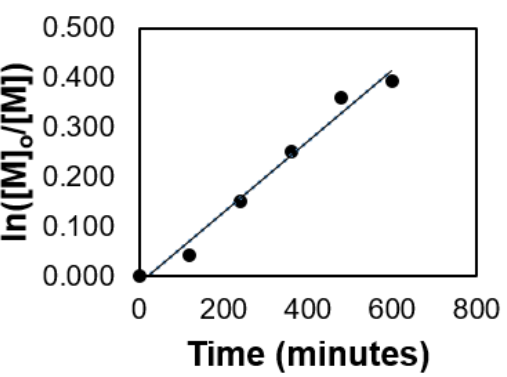

c)

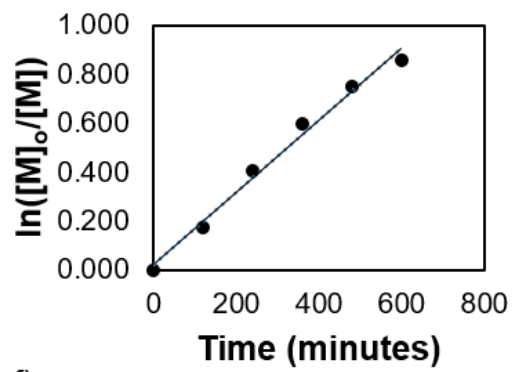

f)

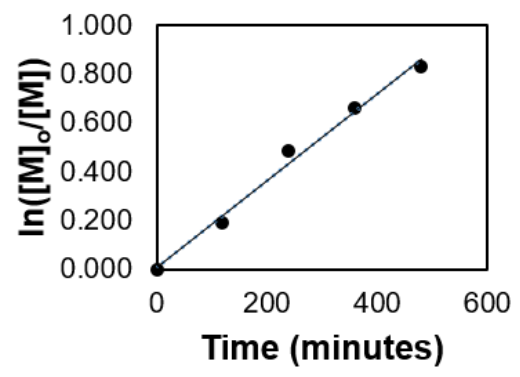

Figure S15. Kinetic plots of $\ln \left([\mathrm{M}]_{\mathrm{o}} /[\mathrm{M}]\right)$ vs time. Entries a-h correspond to entries in Table S1. 


\section{Gel Permeation Chromatography Traces.}

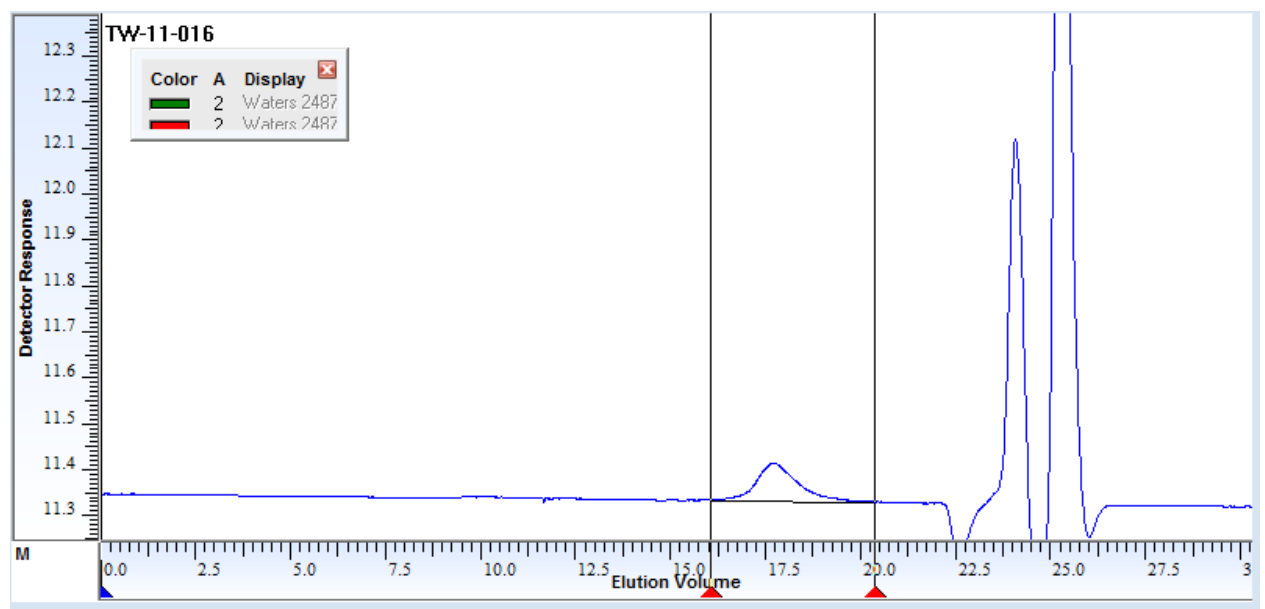

Figure S16. GPC trace of Table S1, entry a.

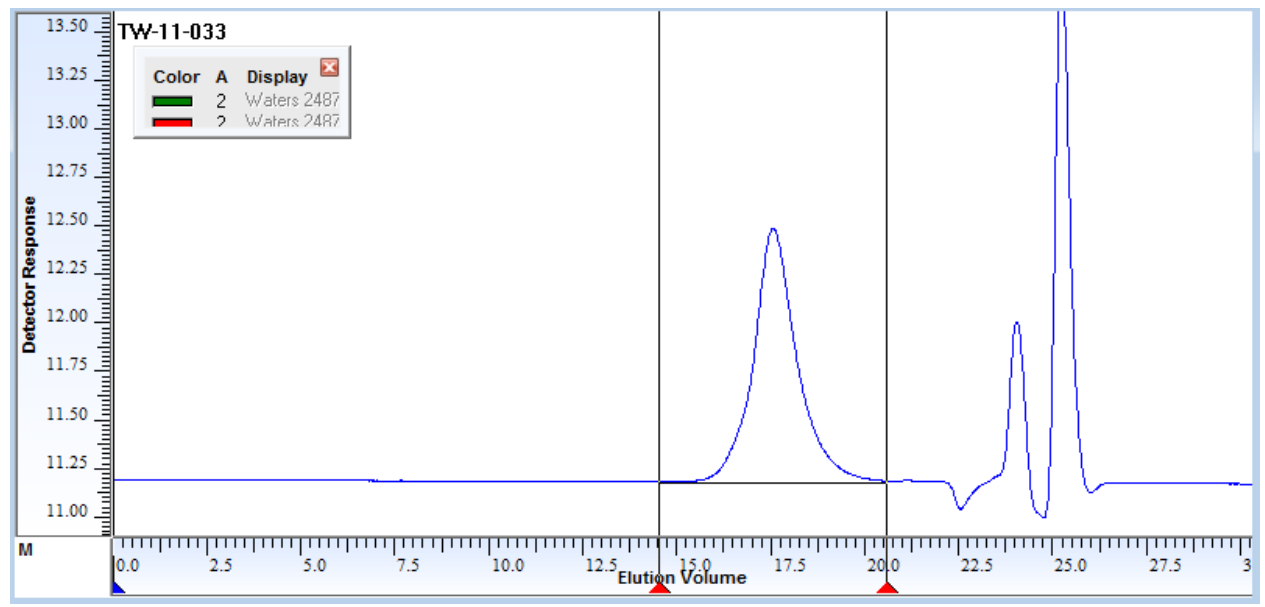

Figure S17. GPC trace of Table S1, entry b.

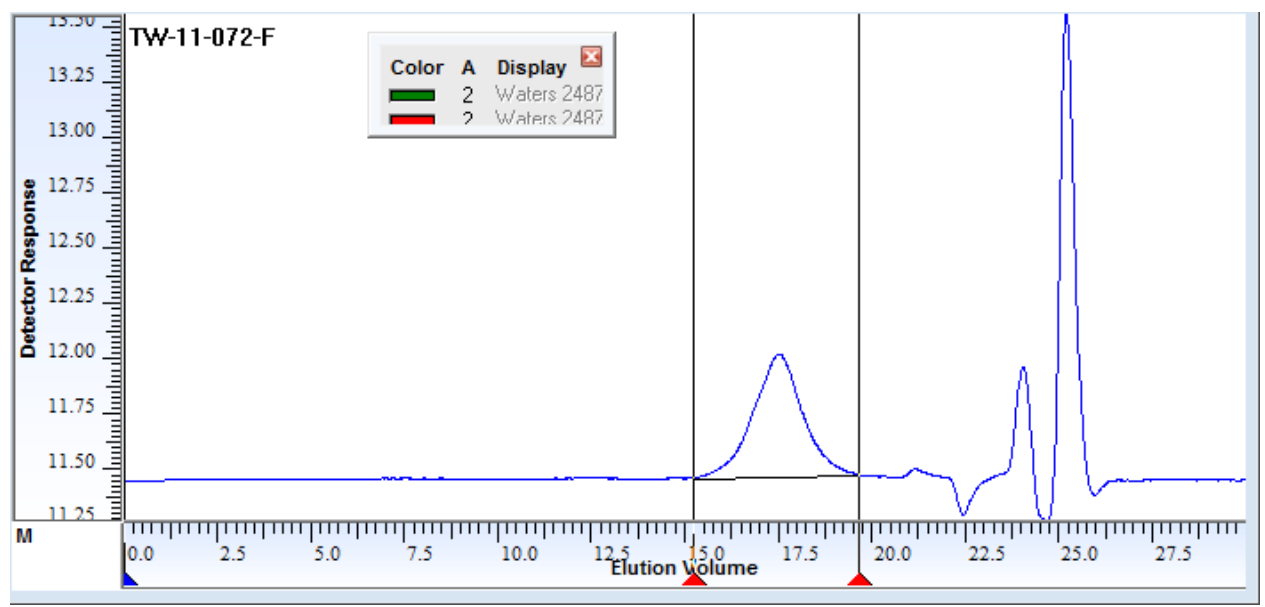

Figure S18. GPC trace of Table S1, entry c. 


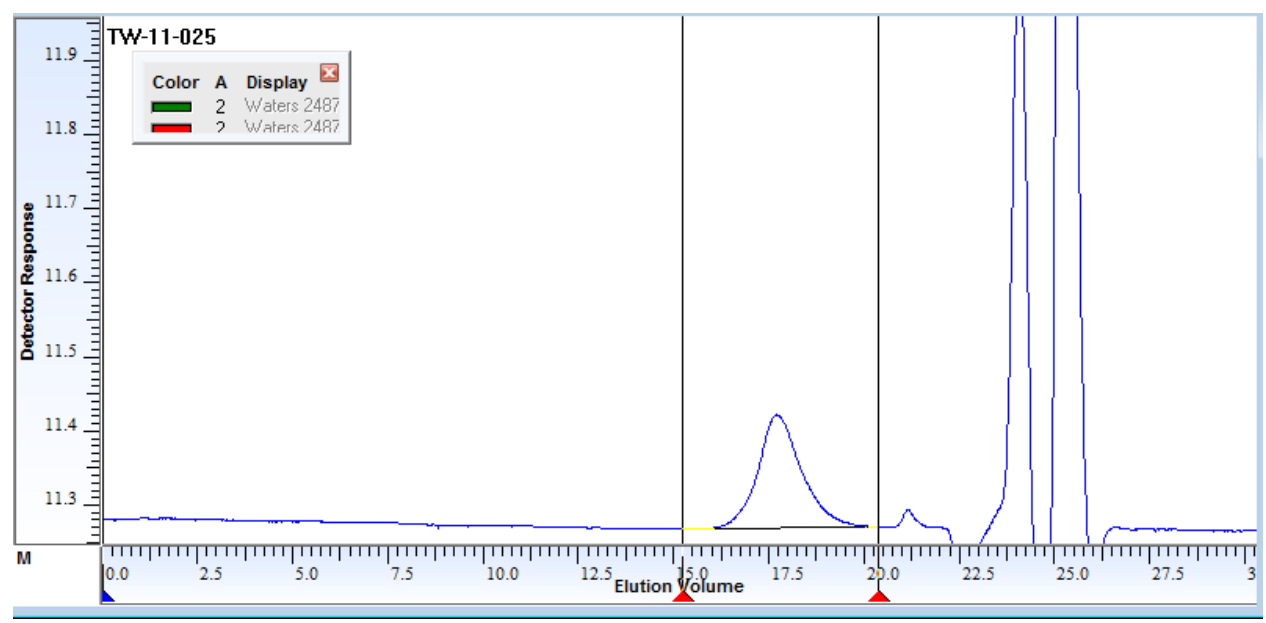

Figure S19. GPC trace of Table S1, entry d.

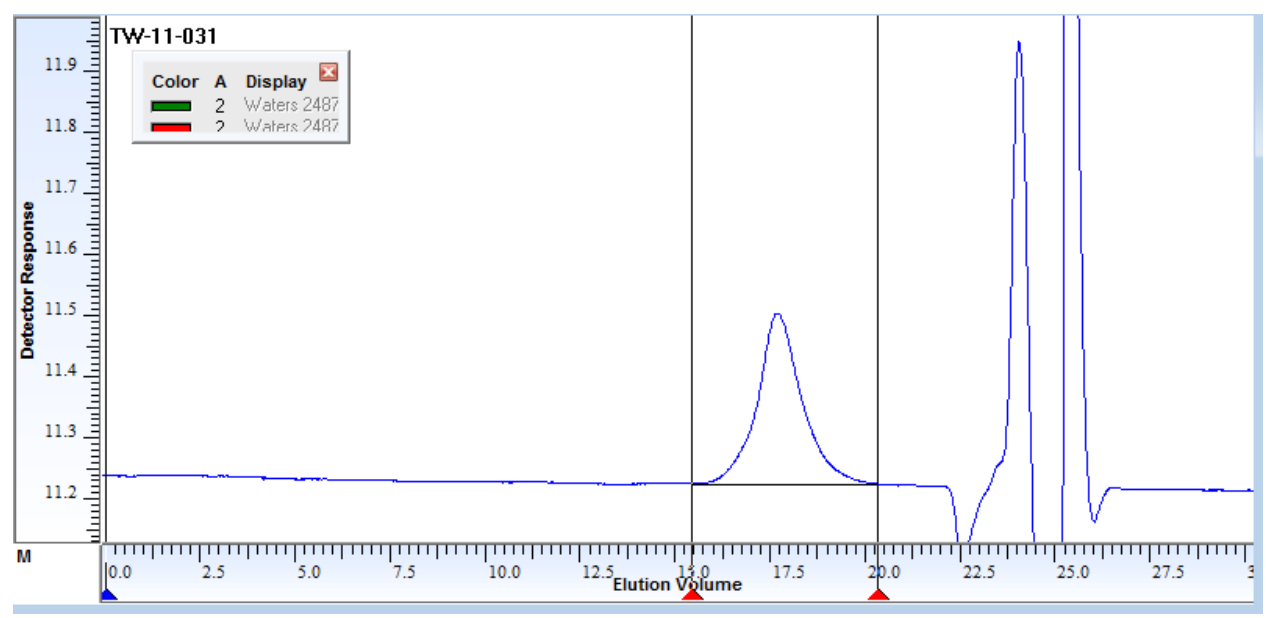

Figure S20. GPC trace of Table S1, entry e.

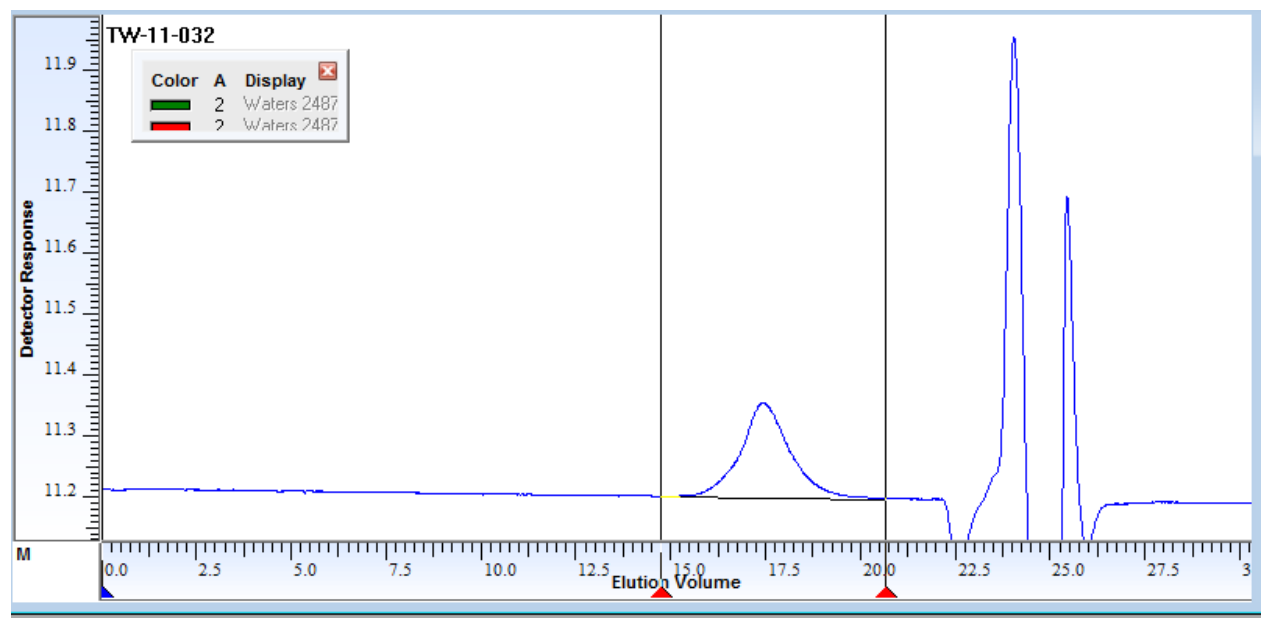

Figure S21. GPC trace of Table S1, entry f. 


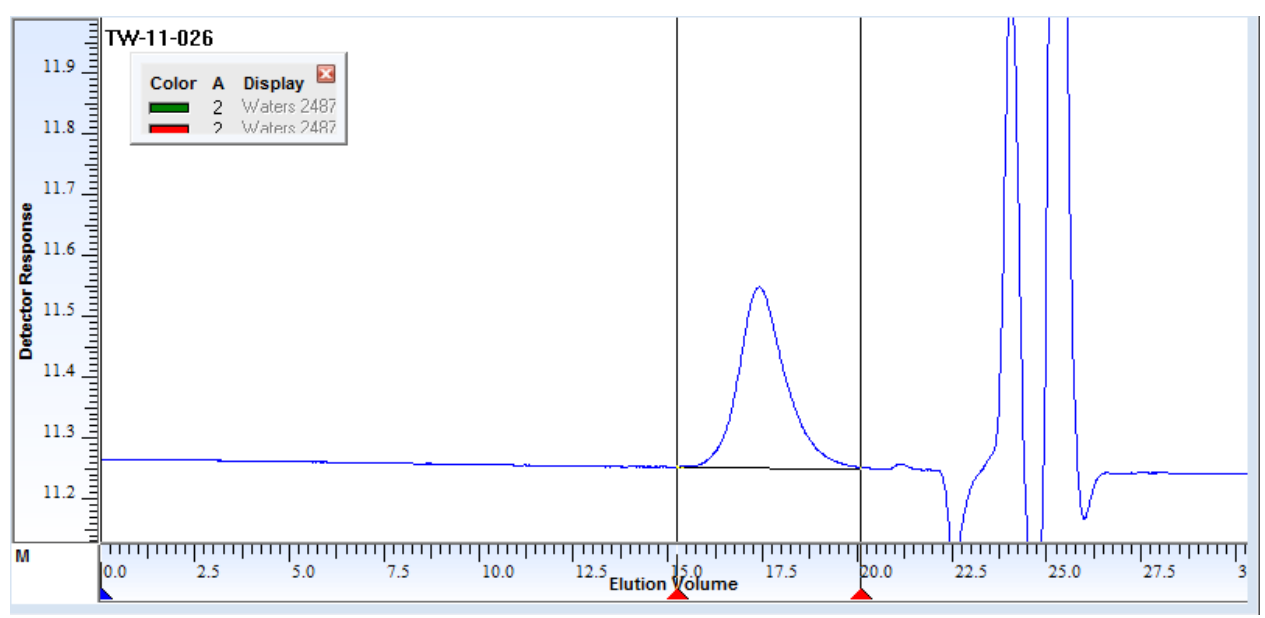

Figure S22. GPC trace of Table S1, entry g.

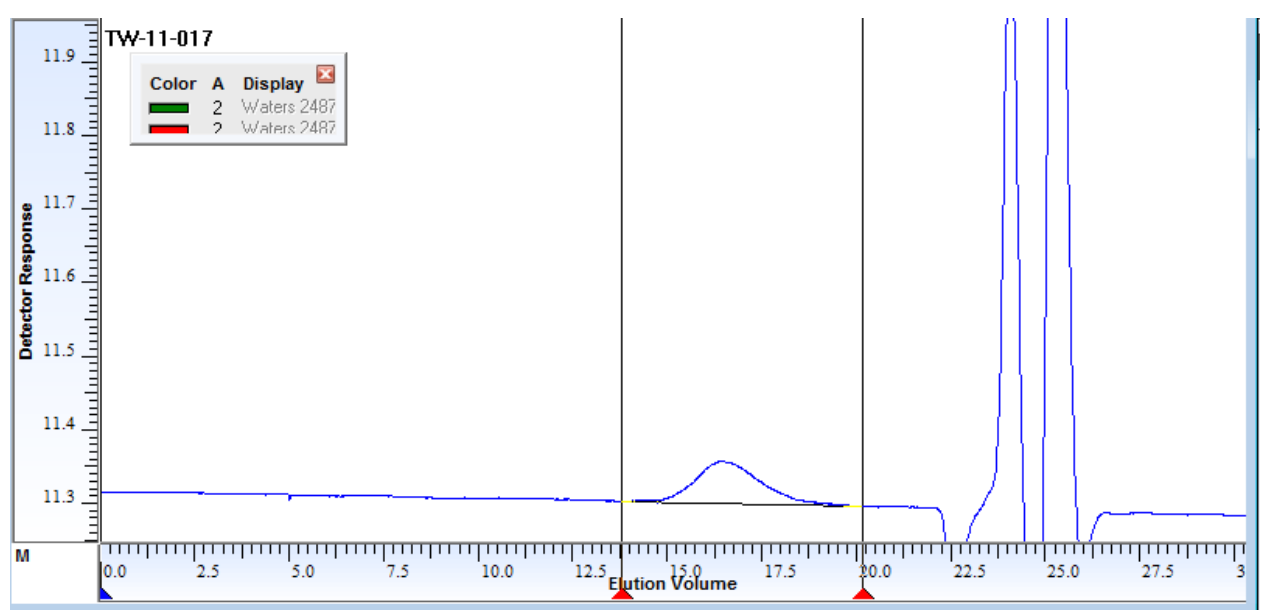

Figure S23. GPC trace of Table S1, entry h. 


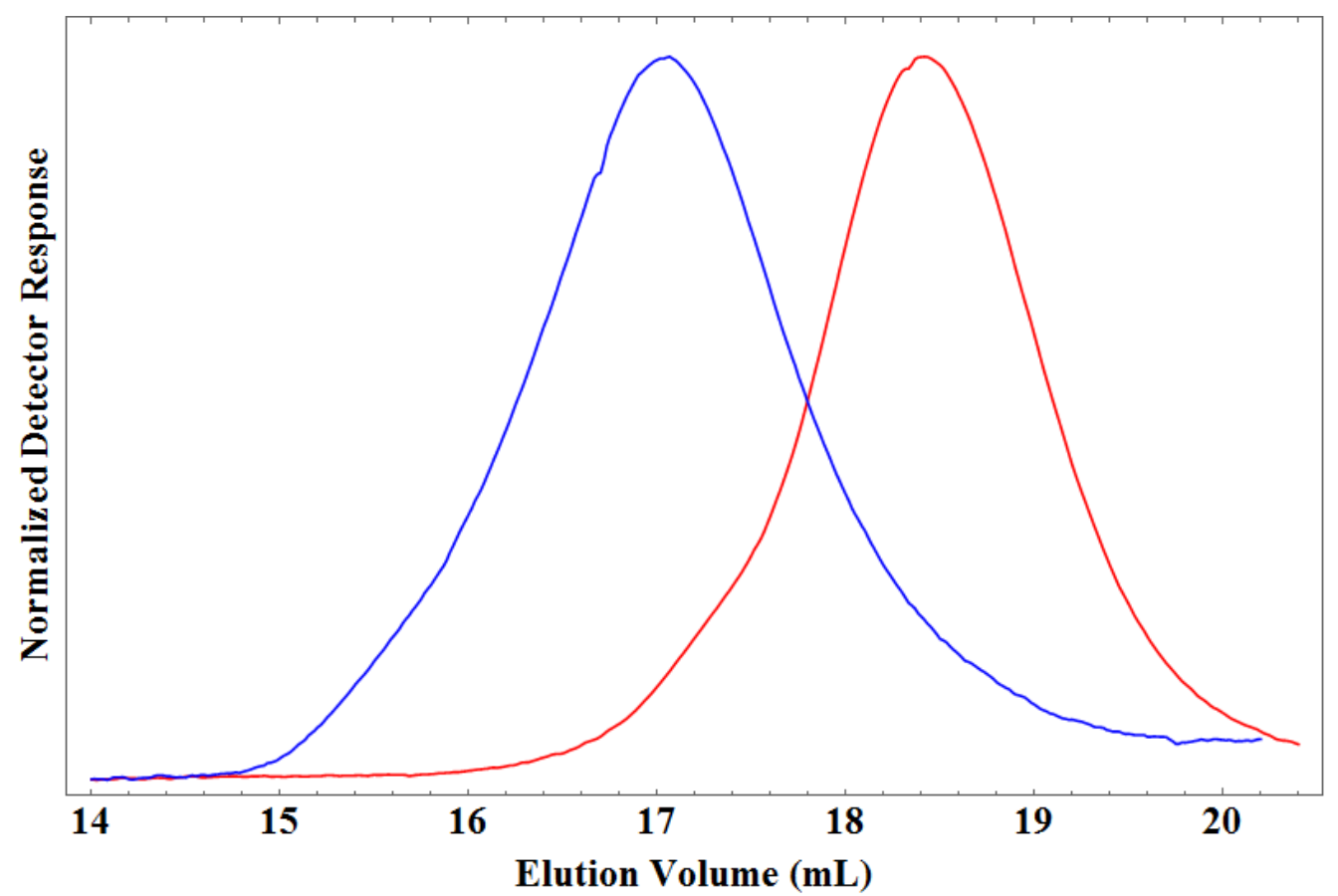

Figure S24. GPC traces for the Polyisoprene macro-RAFT Agent (red, $M_{\mathrm{n}}=10100, Ð=$ 1.23 ) and chain extended block copolymer (blue, $M_{\mathrm{n}}=26000, Ð=1.27$ ). GPC traces were collected using THF doped with $10 \mathrm{mM} \mathrm{Li}\left[\mathrm{NTf}_{2}\right]$ as the eluent. 


\section{Thermal Gravimetric Analysis Curves}

a)

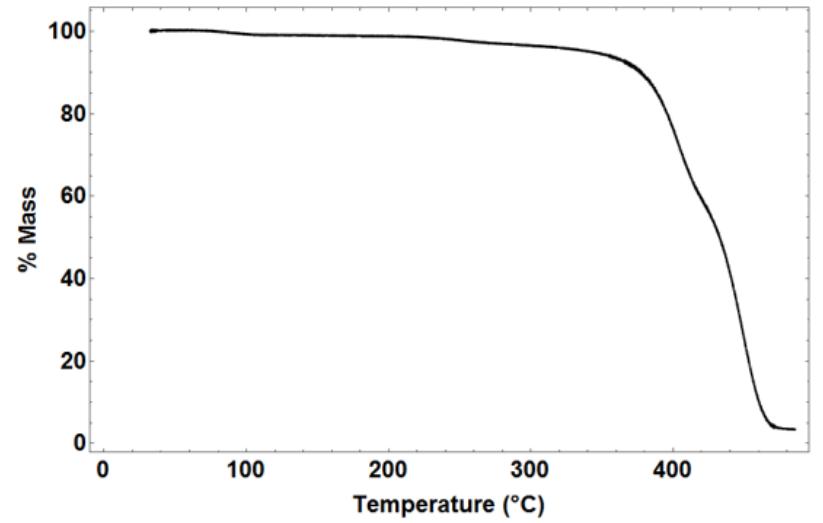

c)

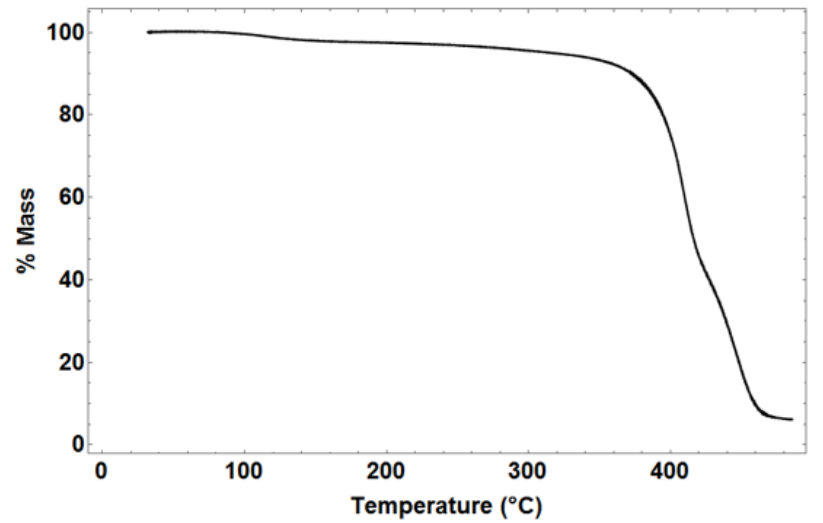

e)

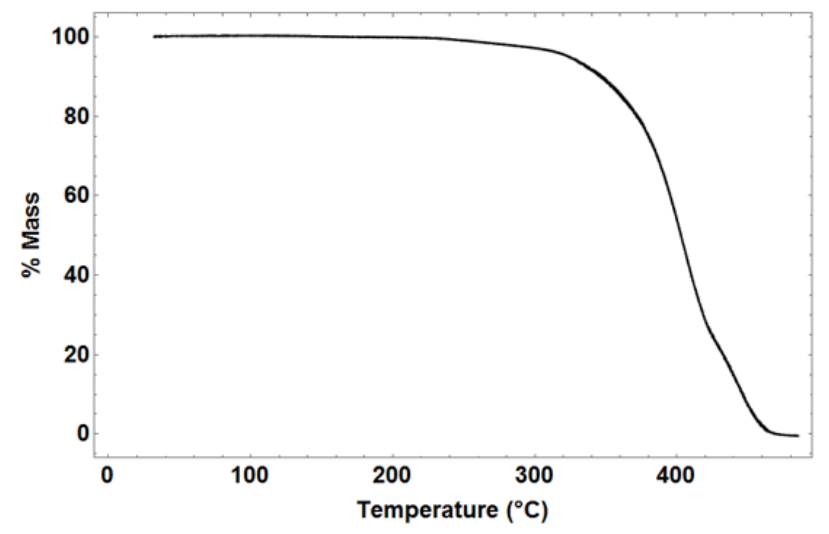

b)

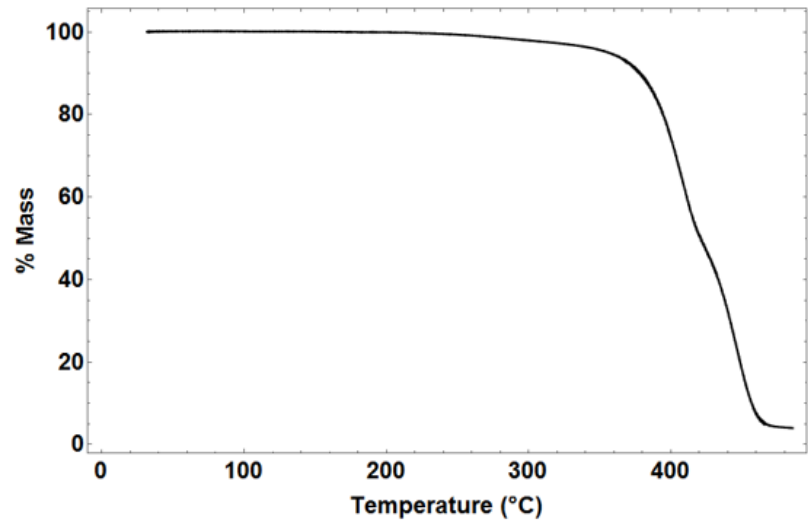

d)

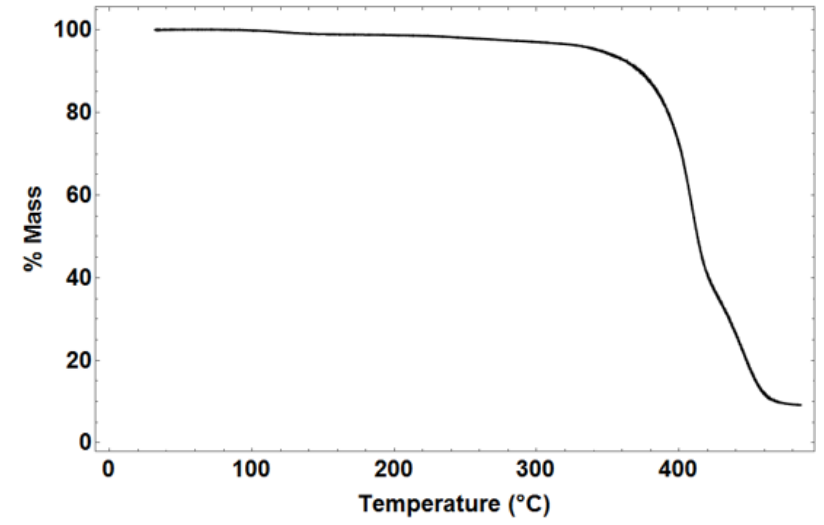

f)

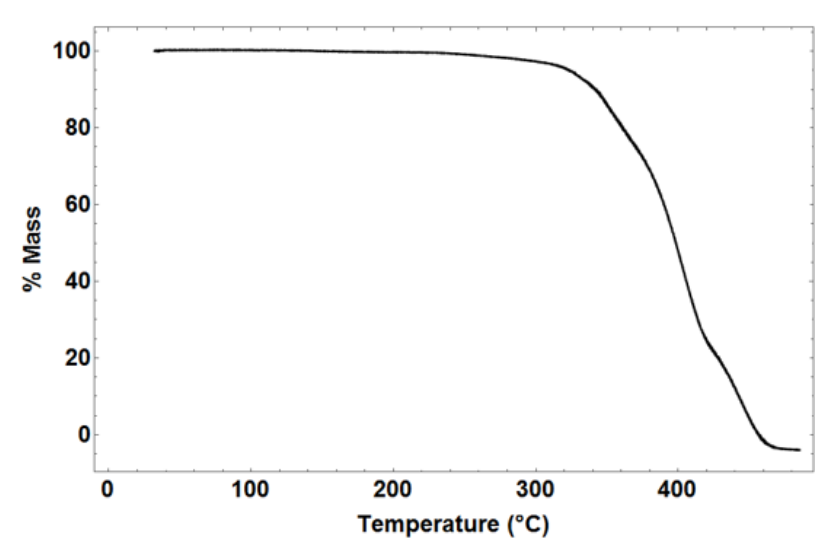

Figure S25. TGA curves of entries a-f (Table S1). 


\section{Differential Scanning Calorimetry Data}

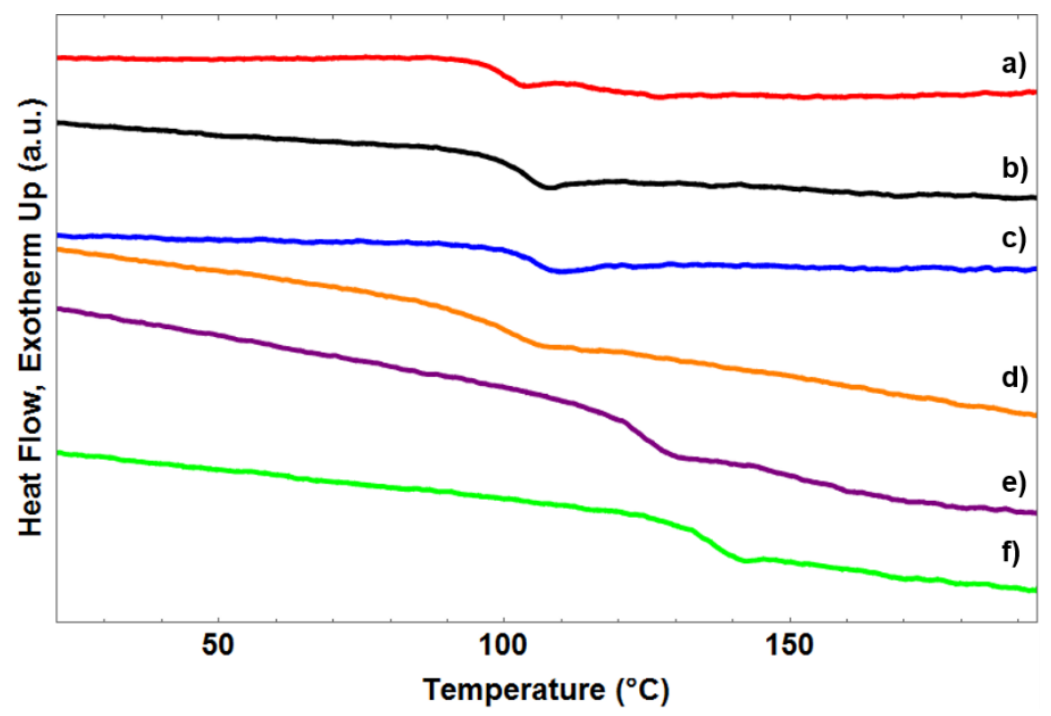

Figure S26. DSC curves of entries a-f from Table S1.

\section{References}

(1) Alonso, F.; Moglie, Y.; Radivoy, G.; Yus, M. Eur. J. Org. Chem. 2010, 2010, 1875-1884.

(2) Dudek, S. P.; Sikes, H. D.; Chidsey, C. E. D. J. Am. Chem. Soc. 2001, 123, 8033-8038.

(3) Jitchum, V.; Perrier, S. Macromolecules 2007, 40, 1408-1412. 